\title{
Landslide hazard mapping in GIS
}

\author{
Ranjan Kumar Dahal \\ Central Department of Geology, Tribhuvan University, Kirtipur, Kathmandu, Nepal \\ (E-mail:rkdahal@gmail.com;ranjan@tugeology.edu.np)
}

\begin{abstract}
Landslides are common geologic hazard occurring in all parts of the world predominantly in the rainy season. In recent years, landslide risk mapping has played an important role in developing land-use planning and it helps to minimize the loss of lives and damages to property. A variety of approaches have been used in landslide hazard and risk assessment and these can be classified into heuristic approach, statistical approach, deterministic approach, etc. An abrupt development of computers after 1990, geographic information systems (GIS) became essential tools for landslide hazard assessment. However, validation and replication is always difficult and there are little works on the satisfactory validation of various approaches. This paper deals with several aspects of landslide hazard and risk assessment by presenting a focalized review of GIS-based landslide hazard and risk assessment with a critical information of the state of the art in using GIS and digital elevation model (DEM) derivative for landslide hazard and risk assessment. This paper also describes some statistical and deterministic approaches and suggests detail step-by-step methodologies. It also describes in brief about integration of various database software and GIS.
\end{abstract}

Key words: landslide hazard, statistical method, GIS, DEM, variable approach

Received: 17 November 2016

Revision accepted: 21 May 2017

\section{INTRODUCTION}

Landslides are the common problems of mountainous terrains of tropical, subtropical and temperate regions and are demonstrated in a variety of processes. Actually, landslides are one of the normal landscape building processes in the mountainous regions and they become a problem when they interfere human activities. Landslides pose serious threats to settlements, and structures that support transportation, natural resources management and tourism. They cause considerable damage to highways, railways, waterways and buildings. Potential sites that are particularly prone to landslides should therefore be identified in advance to reduce disaster damages. Landslide hazard assessment can be a vital tool to understand the basic characteristics of the terrains that are prone to failure especially during extreme climatic events. Landslide hazard zonation is defined as the mapping of areas with an equal probability of occurrence of landslides within a specified period of time (Varnes 1984; Crozier and Glade 2005). Moreover, intrinsic (bedrock geology, geomorphology, soil depth, soil type, slope gradient, slope aspect, slope convexity and concavity, elevation, engineering properties of the slope material, land use pattern, drainage pattern) and extrinsic (rainfall, earthquakes, and volcanoes) variables are used to determine landslide hazard in an area (Siddle 1991; Wu and Siddle 1995; Atkinson and Massari 1998; Dai et al. 2001; Çevik and Topal 2003). The extrinsic variables are site specific and possess temporal distribution. Moreover, they are difficult to be estimated because of lack of information about the spatial distribution. Hence, in landslide hazard assessment practice, the term "landslide susceptibility mapping" is addressed without considering the extrinsic variables in determining the probability of occurrence of a landslide event (Dai et al. 2001; Dahal et al. 2008a,b). In 2008, JTC-1 (Joint International
Society of Soil Mechanics and Geotechnical Engineering (ISSMGE), International Society of Rock Mechanics (ISRM) and International Association of Engineering Geology (IAEG) Technical Committee on Landslides and Engineered Slopes) prepared the guidelines and defined landslide susceptibility and hazard in the prospect of interaction between intrinsic and extrinsic variables as well as frequency of occurrence of the events (Fell et al. 2008). According to JCT-1 definition, landslide susceptibility is a quantitative or qualitative assessment of the classification, volume (or area), and spatial distribution of landslides which exist or may potentially occur in an area. Landslide susceptibility zoning requires an inventory map of landslides occurred in the past together with assessment of the areas with the potential to occurrence of landslides in future but with no assessment of frequency (annual probability) of occurrence (Cascini 2008). Landslide susceptibility map includes landslides which have their source in the area, or may have their source outside the area but may travel through the area or return into the area (Fell et al. 2008; Cascini 2008; Frattini et al. 2010).

A region is considered to be susceptible to landslides when the terrain conditions at that site are comparable to those in the region where a slide has occurred (van Westen 2000). The integrated analysis of all intrinsic variables in relation to the spatial distribution of landslides has gained enormous success by the introduction of Geographic Information Systems (GIS), the ideal tool for the analysis of parameters with a high degree of spatial variability. For a landslide hazard assessment, the assumption is made that conditions, which led in the past to landslides, will also result in potential unstable conditions in the present. Thus, a landslide inventory mapping, differentiating according type, activity, dimensions and so on is primary data for landslide hazard or susceptibility zonation. 
The inventory map also need to cover information of time span based landslide distribution as far as possible. When mapping of intrinsic parameters or causal factors, emphasis should be given to the most relevant terrain parameters related to the occurrence of landslides. Generally, it is true that the selection of intrinsic parameters takes the nature of the study area and the data availability into account. But in a GIS-based technique, it is also necessary to be sure that any selected factor is functional (has a certain degree of affinity with previous occurrences of landslides), complete (is reasonably represented all over the study area), no uniform (remarkable spatial variation), measurable (can be expressed by nominal, ordinal, interval, ratio scales), and non-redundant, i.e., outcome of selected factors should not account for double effects in the final result (van Westen 2000; Yelcin 2008). Geomorphological hazard mapping and analysis of landslide inventories are two basic expert knowledge-based qualitative landslide hazard mapping techniques. Geomorphological mapping of landslide hazard is a direct, qualitative method that relies on the ability of the investigator to estimate actual and potential slope failures. When making use of GIS techniques, the following methodological approaches can be differentiated (van Westen 2000):

Heuristic qualitative approach: particularly suited for smallscale regional mappings. The scale of such mappings is in the order of 1:100,000 to 1: 250,000 scales and suitable for regional scale planning.

Statistical quantitative approach: used by consulting firms or planning agencies for the preliminary planning of infrastructural works, such as the definition of road corridors and use the range of 1: 25,000 - 1: 50,000 scales. This scale can be sub differentiated as data driven multivariate statistical analysis and experience driven bivariate statistical analysis.

Deterministic approach: for detailed studies at large scale (1: 2,000-1:10,000), without entering at the level of the engineering geological site investigation. Such small-scale studies are used by consulting firms or local planning agencies for the detailed planning of infrastructural works. The deterministic and statistical methods are also called quantitative methods (Aleotti and Chowdhury 1999) and are based on numerical expressions of the relationship between intrinsic factors and landslides. In the statistical approach, input and output data related to by an empirical parametric function. The parameters used in this function are not related to physical parameters that can be determined in the field or in the laboratory. The underlying physical process is absent or neglected in the statistical approach of landslide hazard modelling. By using statistical approach, temporal prediction of hazard is possible provided that extreme events are present in the data set, which was used to the derivation of the statistical model. There are various models available in statistical approach. Examples of the statistical approach include discriminant analysis (Carrara et al. 1991), multivariate regression analysis (Jade and Sarkar 1993; Atkinson and Massari 1998; Ohlmacher and Davis 2003; Komac 2005; Guzzetti et al. 2006) and Bayes learning (Lan et al. 2004). In addition, hybrid methods were also developed by combining statistical approaches and artificial neural networks (ANN). Hybrid methods include ANN-fuzzy logic (Kanungo et al. 2006), ANN-Bayes analysis (Lee et al. 2004) and Bayes analysis-decision tree (Ayalew et al. 2004). However, information value method, weights-of-evidence, logistic regression, weighted linear combination, analytical hierarchy process, fuzzy logic, artificial neural network, and support vector machine are some of the well discussed methods in literatures (Yin and Yan 1988; Soeters and van Westen 1996; Wieczorek et al. 1996; Crozier 1999; Guzzetti et al. 1999; van Westen 2000; Lee and Min 2001; Dai and Lee 2001, 2002, 2003; Dai et al. 2001; van Westen et al. 2003; Dai et al. 2004; Lan et al. 2004; Süzen and Doyuran 2004; Zêzere et al. 2004; Ayalew and Yamagishi 2005; Ermini et al. 2005; Yesilnacar and Topal 2005; Saha et al. 2005; Kanungo et al. 2006; Komac 2006; Sharma and Kumar 2008; Yao et al. 2008; Yelcin 2008. Complete overviews of the use of GIS for statistical landslide susceptibility assessment can be also found in van Westen (1994), Aleotti and Chowdhury (1999), Guzzetti et al. (1999), Dai et al. (2001), Çevik and Topal (2003), Fall et al. (2006), Dahal et al. (2008a), Dahal et al. (2008b), Dahal et al. (2008c), Fell et al. (2008), Cascini (2008), Pradhan and Buchroithner (2009); Frattini et al. (2010); Pradhan and Lee (2010); Dahal et al. (2012). The deterministic approach is also called physically based approach. The deterministic quantitative methods depend on engineering principles of slope instability expressed in terms of the factor of safety. They are based on the physical-mechanical laws of conservation of mass, energy and momentum and the equilibrium of forces. The parameters used in deterministic approach can be derived in field or laboratory and can be used for spatial as well as temporal prediction of landslide hazard. Due to the need for exhaustive data from individual slopes, these methods are often only effective for mapping small areas. GIS application in slope stability analysis is not just limited to the spatial and non-spatial database generation and manipulation but it also assists in modelling, as different physically based models can be readily integrated in it. A coupled approach incorporated in GIS, combining hydrological and slope stability parameters, is commonly adopted to facilitate the simulation of slope stability. Deterministic models which were traditionally used to calculate the stability of individual slopes, with the advent of GIS and its data handling capabilities, have also been successfully applied over larger areas such as catchments (Montgomery and Dietrich 1994; Pack et al. 1998) and road corridors (Hammond et al. 1992). There are few examples of GIS-based deterministic models in literatures. In these models, both topographic as well as engineering properties of slope materials can be used to prepare deterministic landslide hazard zonation map. Montgomery and Dietrich (1994) and Dietrich et al. (1995) developed a contour- or polygon-based hill slope hydrological model called SHALSTAB. This model considered some of the index properties of slope materials, and can be implemented as an extension of commercially available GIS software (ArcView and ArcGIS). Pack et al. $(1998,2001)$ developed another approach (SINMAP), which is suitable for modelling slopes that have a shallow soil depth and impermeable underlying bedrock. It is similar to SHALSTAB, but uses cohesion and root cohesion (for forested 
slopes) in the calculations. Thus, SINMAP may be viewed as an advanced version of SHALSTAB. The contributing area is one of the important topographic parameters used in SINMAP. CHASM is a hydrological-slope stability model developed by Bristol University, links a finite difference hydrological model with Bishop's rotational slope stability model. A PC-based integrated dynamic slope stability model, IDSSM (Dhakal and Sidle 2004), a modified version of dSLAM, examines the influence of different rainstorm characteristics on landslide initiation. TRIGRS, acronym for Transient Rainfall Infiltration and Grid Based Regional Slope Stability, is a FORTRAN program for computing transient response of pore-pressure due to rainfall infiltration and consequent changes in the safety factor. It is based on the Iverson's method (Iverson 2000) and is modified by including the solutions for additional basal boundary conditions and a runoff-routing scheme (Baum et al. 2002). These models are capable to result spatial distribution of slope instability in terms of the factor of safety. Gökceoglu and Aksoy (1996), Terlian (1996), van Westen and Terlian (1996), Glade et al. 2000), Dhakal and Siddle (2004) are some attentive examples of deterministic landslide hazard study.

\section{GIS AND DATA PREPARATION}

When GIS techniques are employed for landslide hazard analysis, it is important that each data-layer map be composed of only one type of data element (points, lines, or areas and polygons) and have one or more accompanying tables to define the characteristics of each. Of course, the data layers required by landslide hazard analysis may vary to account for the characteristics of different environments. Any spatially distributed data with a geo-reference to real world could be stored as points, lines and polygons (vector model) or as continuous fields (raster data model).

The landslide information of an area can be overwhelming and the need to put managed way for timely decisions and planning. GIS tools help to present the information in useful ways. GIS allows to bring all types of landslide data together based on the geographic component of the data. Unlike a static paper map, GIS can display many layers of information that is useful to assess a particular problem of landslides. It also helps to integrate, visualize, manage, solve, and present the information in a new way. Relationships between the data will become more apparent and data will become more valuable. GIS provides the power to create landslides related maps, integrate information, visualize scenarios of failures, solve problems, present powerful ideas, and develop effective solutions. In particular, GIS has ability to present the data, produce results in map forms. It also has capability of interactive visualization in a spatially optimized mode. Thus, it plays a key role in identifying the critical areas, where more rigorous analysis and improved solution is required.

The landslide processes are related to a variety of factors relating to both the natural environment and human activities. Therefore, landslide hazard mapping requires many data about causative factors like rock type, geologic structure, land use, hydrology etc. For this reason, landslide hazard mapping procedures entail multidisciplinary works.

\section{Input data for landslide hazard mapping}

In order to prepare a landslide hazard map, various data needs to be combine. The combination is performed with various statistical procedures. The input data required for assessing landslide hazard at the regional, medium, and large scales of mapping are well described by Soeters and van Westen (1996). Each input data may be represented by an individual map. The input data layers required for landslide hazard mapping may vary to account for the characteristics of different natural environments. Some of the essential input data can be categorized into the following factor maps.

(a) Geological and engineering geological maps: They show the different types of rock units and their spatial distribution in an area, engineering soil of the area, with information on geotechnical index parameters.

(b) Digital Elevation based morphometric maps: They show quantitative information about the landforms, such as altitude, slope angle, slope aspect, concave slope, convex slope etc. These maps are derived from Digital Elevation Model of the area.

(c) Soil thickness map: Map having information about thickness of the soil cover in the study area.

(d) Geomorphological map: It shows a subdivision of the terrain in landforms, generated through different geological processes like, glacial, fluvial, etc.

(e) Groundwater table maps: They show the depth of the groundwater for different periods, related to different amounts of rainfall. These maps especially needed for deterministic landslide hazard analysis.

(f) Land use map: Map having information about various types of land use and land cover in the area. Such map can be derived from satellite image interpretation, aerial photo interpretation and field mapping.

(g) Seismic acceleration map: It shows the acceleration related to earthquakes with a certain return periods, and basically suitable in deterministic landslide hazard mapping.

(h) Hydrological and hydrogeological maps: They show the drainage network, catchments, spring and seepage zones. Similarly, flow accumulation, sediment transport index, wetness index are also used for hazard analysis. These maps are prepared either through image and photo interpretation or from existing topographic maps.

(i) Human intervention maps: Human intervention in the natural environment always facilitates landslide processes on mountainous region. Programs such as road construction, irrigation canal construction, improper irrigation practice, unconventional housing on slopes and improper cut-andfill always elaborate landslide risk. Therefore, in statistical analysis, causatives maps such as distance to roads or distance to irrigation canals are widely used in analysis.

(j) Landslide inventory maps: They show the location, types, activities and component parts of landslide, like scarp area, transportation zone, or accumulation zone. In the statistical landslide hazard analysis, without landslide inventory, hazard zonation is not possible. Similarly, for the deterministic landslide hazard analysis also, landslide inventory maps are useful to validate model and to interpret the accuracy of the zonation maps 


\section{Landslide inventory map}

Preparation of a landslide inventory map is the basic approach of landslide hazard mapping. By the help of aerial photo interpretation, field survey, historical data of landslide occurrences and literature collection help to prepare landslide inventory map. Such map contains the spatial distribution of landslide, represented either at polygons or as points and can be used as an elementary form of hazard map.

Landslide inventory maps do not provide insight into temporal (time dependent) changes in landslide distribution. Such maps lack many landslides that occurred sometime before the time of aerial photographs taken as well as fieldwork conducted. Enhancement can be done by the help of interpretation of aerial photographs of different time (multi temporal) and data of different field visit. Landslide inventory mapping also helps to prepare landslide density maps. For regional scale of landslide mapping, preparation of inventory maps is some-what not applicable because scale does not permit to represent many landslides of smaller size. During regional scales of landslide hazard mapping, landslide inventory is a prime parameter necessary for heuristic or statistical approach.

Similarly, according to JTC-1 (Joint Technical Committee - 1, International Society of Soil Mechanics and Geotechnical Engineering) guidelines, a landslide hazard map is complete when it includes the information about the landslide magnitude probability, the landslide spatial distribution probability and the landslide temporal variation probability (Fell et al. 2008). However, it is always not possible to obtain information about magnitude, spatial and temporal probabilities of landslides for all regions. As a result, landslide susceptibility is the alternative way to express the landslide hazard. Another, alternative way to address the magnitude, spatial and temporal probabilities is to define proxy parameters. For example, magnitude can be expressed by a proxy parameter such as area of landslide (Guzzetti et al. 2006). Similar, proxy parameters can be defined for the spatial and temporal probabilities, for example, the temporal distribution of landslides can be used as a proxy of extrinsic parameters and landslide hazard map can be produced.

\section{HEURISTIC APPROACH OF LANDSLIDE HAZARD MAPPING}

In heuristic methods, basically geomorphological survey is done to classify the landslide hazard. Expert opinion plays a direct role in classifying hazard. The mapping of landslide and their geomorphological setting are the main input factor for hazard determination. In general, two types of heuristic approaches have been in practice (Soeters and van Westen 1996) for landslide hazard mapping.

\section{Geomorphological analysis or direct mapping approach}

The hazard is mapped directly in the field by an experienced geomorphologist or geologist. During mapping, especial attention is given to the geomorphological setting of the slopes. In 90s, this methodology was in widely practice for road corridor and irrigation canal landslide hazard mapping. The main drawback of this method is that the product maps vary from place to place and may be different from experts to experts in a single place. In the recent days, the use of such approach has been replaced by statistical approach. An example of geomorphological analysis for landslide hazard mapping is shown in Fig. 1.

\section{Qualitative methods}

Qualitative methods of landslide hazard mapping are based on qualitative map (geological map, land use map, slope map, hydrological maps, human intervention parameter maps (such as road, canal, and trail), hydrogeological map, and so on) combination. In a qualitative map combination, the weight values are allocated to series of parameter maps (Fig. 2) and each parameter map receives different weight. The allocated weights are then sum up and these values are used for hazard classification. The range values of sum up weights are grouped into hazard classes as low, moderate and high. This method of hazard mapping is widely used in landslide study. This method can be applied to regional, medium and large-scale mapping. Statistical approach is now replacing this method and now very few works appear in research articles.

\section{Statistical Approach}

The statistical landslide hazard analysis deals with the groups of factors that have led to landslides in the past. Such factors are determined statistically and quantitative (amount or number) predictions are made for landslide free areas with similar failure conditions. Bivariate and multivariate statistical analyses are two types of statistical approaches currently in practice for landslide hazard analysis. In this approach, the interaction between one parameter and another parameter is statistical only. In calculation, there is no physical law and interaction. As a result, statistical approach is also called black box model.

\section{Bivariate statistical analysis}

In bivariate statistical analysis, each parameter map (geology, slope, hydrology, land use etc.) is combined with the landslide inventory map and weight values for each parameter class (slope class, rock types, land use etc) are obtained on the basis of landslide distribution in the area and causative class itself. Finally, the weight value is summed to obtain landslide hazard index (LSI). In many cases, same landslide data are used for both hazard assessment and validation. However, in recent practice, old landslide data are used for hazard modeling and new landslide data are used for model validation. To check capability of LSI values to predict landslide occurrences can be verified by the help of success rate (Chung and Fabbri 1999) curve and effect analysis (Lee 2004, Lee and Sambath 2006, Dahal et al. 2008a). The success rate indicates how much percentage of all landslides occurs in the classes with 


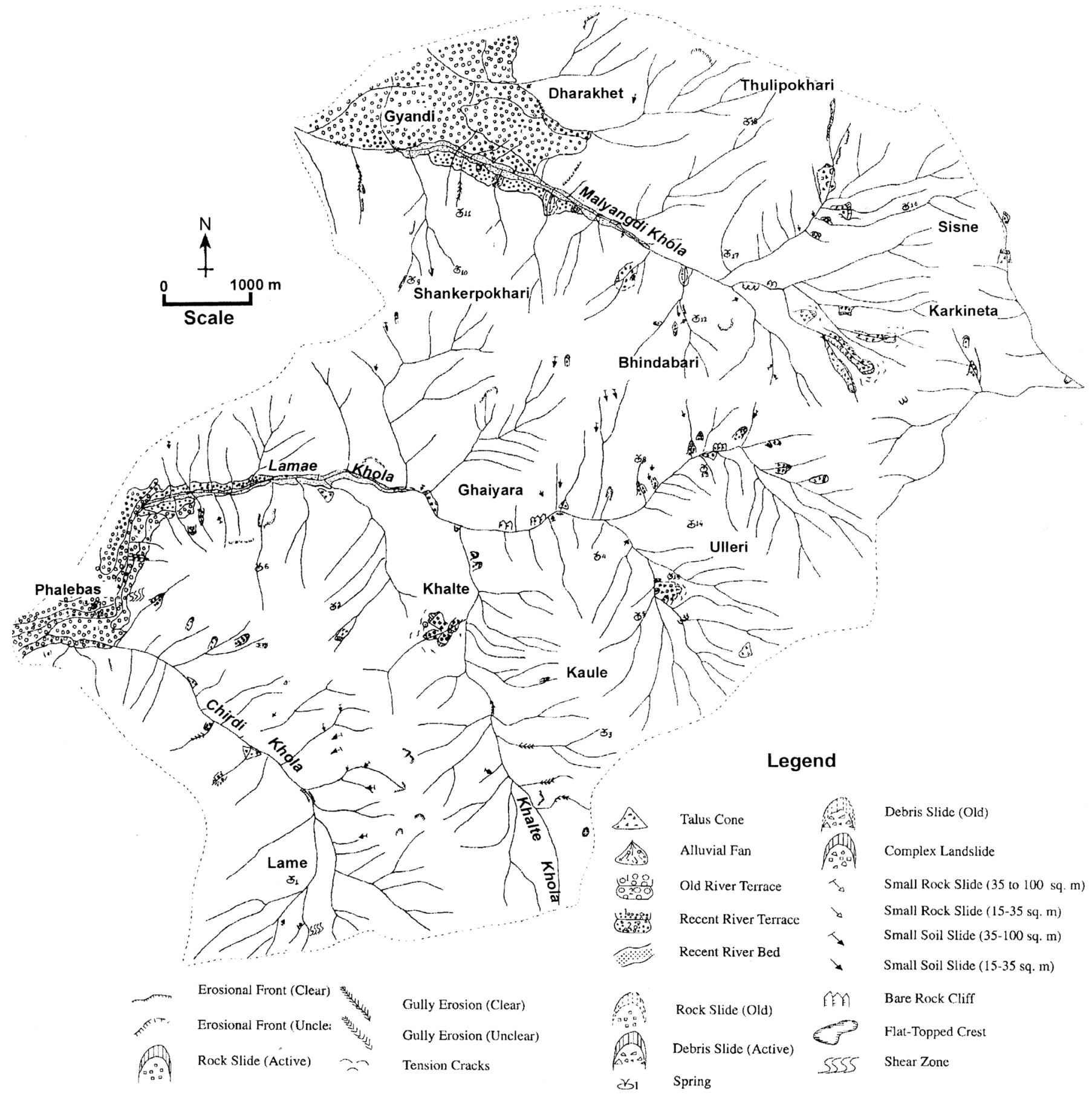

Fig. 1: A map representing geomorphological analysis of a landslide prone area of western Nepal (After Dhital et al. 2002).

the highest value of susceptibility maps. Effect analysis helps to validate and to check the predictive power of selected factors and classes that are used in susceptibility analysis. The distribution frequency of existing landslides in higher LSI is use to prepare success rate curve. It is a measure of goodness of fit of the model. The curves can be created by plotting class group (from $1 \%$ to $100 \%$ ) of high to low hazard value in $\mathrm{x}$-axis and respective value of landslide pixel percentage in each class group in y-axis. The success rate curve helps to identify the classification boundary of LHI value to prepare landslide hazard zonation map with various hazard categories (Fig. 3). If new landslide data available, old landslide data can be used for hazard modeling and new landslide data can be used for validation of model. In this condition, the success rate curve is called prediction rate and it validate landslide hazard index independently (Chung and Fabbri 1999; van Westen et al. 2003; Remondo et al. 2003; Lee et al. 2007; Lee 2004; Dahal et al. 2012; Regmi et al. 2010; von Ruette et al. 2011). 
Dahal, R. K.

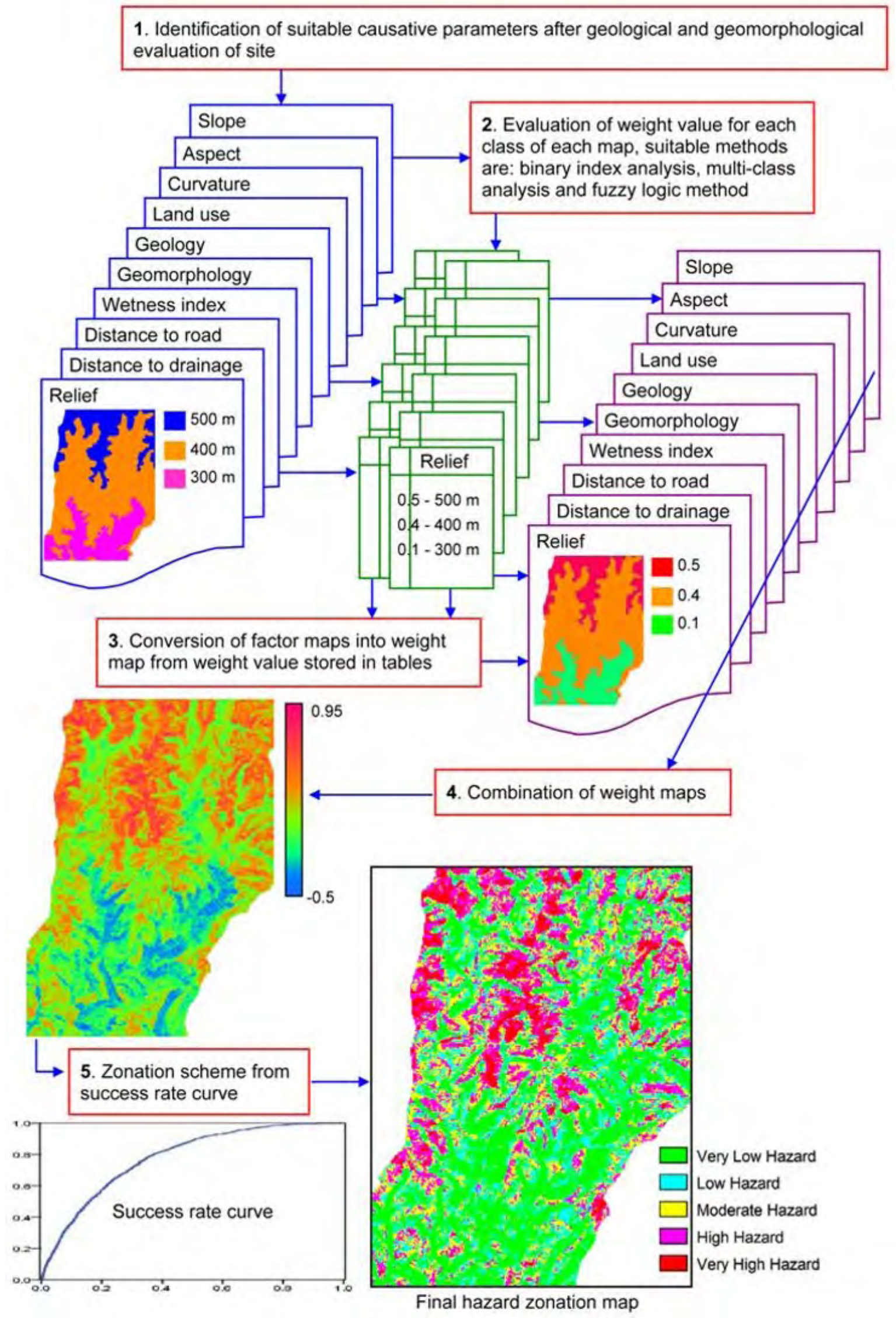

Fig. 2: Qualitative methods of landslide hazard mapping. 


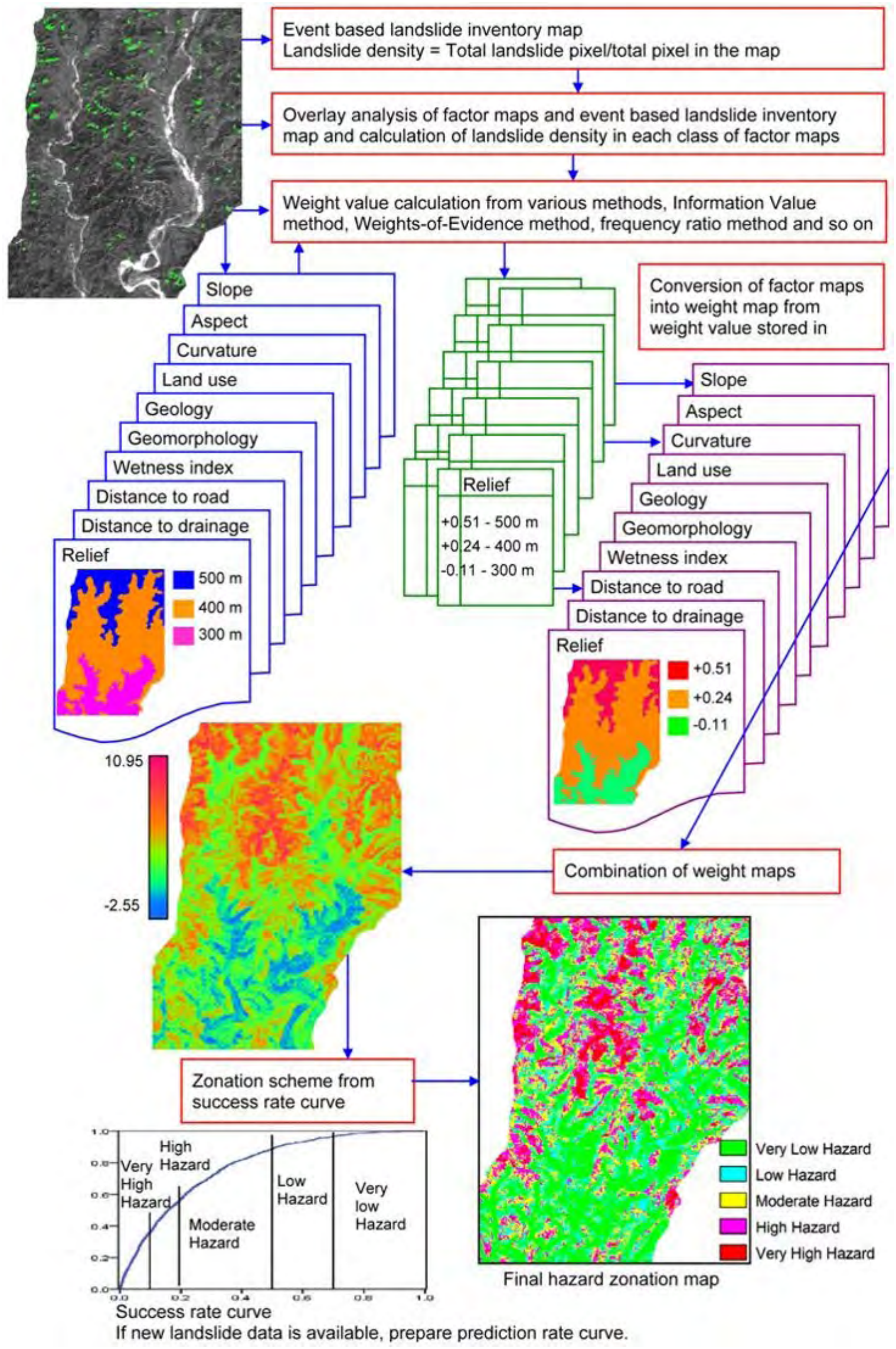

Fig. 3: Work flow of bivariate statistical analysis for landslide hazard mapping. 
Similarly, according to the new approach described by JTC1 , to evaluate landslide hazard by statistical method, annual spatial and temporal probabilities of landslide are always needed to include in landslide hazard map, otherwise the landslide hazard map is only susceptibility map. However, proxy parameters can help to define spatial and temporal probabilities of landslide (Guzzetti 2005). If event based landslide data is available, it can be referred as temporal probability and landslide hazard zonation mapping is possible.

\section{MULTIVARIATE STATISTICAL ANALYSIS}

Multivariate statistical analysis method was initially developed by Carrara (1983). In this type of analysis, all relevant causative parameters are sampled either on a large grid basis (network of evenly spaced horizontal and vertical lines on a map), or in morphometric units. The morphometric units can be differentiated according to the slope angle or slope aspect, relief or slope curvature. For each slope mosaic or morphometric unit, the presence or absence of landslides is determined. The resulting matrix is analyzed using multiple regression or discriminant (method for finding likelihood) analysis. This gives hazard scores for each unit. The hazard scores are used to classify the unit either as stable or as unstable.

In recent years, the multivariate techniques have been elaborated with various approach of sampling. Basically, logistic regression and Artificial Neural Network (ANN) methods are two commonly practiced multivariate modeling methods (Fig. 4). For the logistic regression, the current literatures have been establishing mainly three kinds of practices (Zhu and Huang 2006). First one is using data from all over the study area, which leads to unequal proportions of landslide and non-landslide pixels (Guzzetti et al. 1999; Ohlmacher and Davis 2003). Usually, large volume of data is taken in this method. Second practice is using all the landslide pixels and equal non-landslide pixels, which leads to decrease in data number. The third practice is using all landslide pixels and equal number of randomly selected pixels from areas free of landslides (Yesilnacar and Topal 2005). As the dependent variable is dichotomous and the relationship between the dependent variable and independent variables is nonlinear, logistic regression model can be used on the causative factors. The causative parameters can be categorized into various classes and each parameter is usually nominal variable. The categorized causative variables can be converted into a nominal to a numeric by coding. For this purpose, the landslide density (Carrara 1983) concept can be used to transform nominal variable to numeric variable of each class category of causative parameters. The landslide density can be used to transform nominal variable to numeric variable. It also avoids the creation of an excessively high number of dummy variables.

In the ANN method, using data from all over the study area with landslide pixels is possible. However, it needs many iterations to get suitable result from training data set and testing data set.

\section{DETERMINISTIC APPROACH}

If the geomorphological and geological conditions are fairly homogeneous over the entire study area and the landslide types are also simple, the deterministic method of landslide hazard mapping is used. This method is widely used in hazard analysis of small areas or in large scale. This method is based on slope stability analysis and allows us to calculate quantitative values of slope stability, i. e. factor of safety. Thus, the causative parameters considered in the analysis used with physical law and interaction to parameters to parameters are always there. Therefore, this method is also called white box approach. The main disadvantage of this method is the oversimplification of landslide processes and the necessity of large amounts of reliable input data derived from laboratory tests and field measurements. So, this approach is only suitable for mapping small areas at large scales. An approach of deterministic landslide hazard analysis is shown in Fig. 5. This approach clearly shows that detail field work and laboratory work is necessary to collect data. There are so many uncertainties in the geotechnical properties of soil in each pixel of map.

Therefore, the error propagation is necessary for soil parameters such as cohesion and unit weight. The simple error propagation method based on variance and expected mean helps to find z-value of factor of safety and the z-value gives probability failure. In deterministic method, rainfall is considered as the major parameters in analysis. If the hazard map also covers landslide hazard associated with earthquake triggered landslide, seismic ground acceleration also needs to be incorporate in the analysis (van Westen and Terlian 1996).

\section{REPLICATION OF LANDSLIDE HAZARD INDEX}

Replication of landslide hazard or susceptibility index from one area to other area is always a problem and this is one of the limitation of existing landslide hazard zonation procedure. However, if the causative parameters are similar to the model area, the replication is possible. Landslide hazard or susceptibility index (LHI or LSI) value calculated from bivariate or multivariate analyses can be replicated when hazard or susceptibility analysis is performed in catchment scale. During replication process, the weight of each class of each parameter obtained from one catchment can be used for other catchments if they have similar causative parameters with similar class. An example of replication in multivariate statistical analysis is described in the case studies. The general replication procedure is given in Fig. 6 .

\section{Case Studies}

To demonstrate the principals of landslide hazard mapping, some case studies of statistical approach of landslide hazard mapping are described.

\section{Case 1 - Bivariate statistical analysis}

\section{The study area}

The study area is located in the south-western hills of 


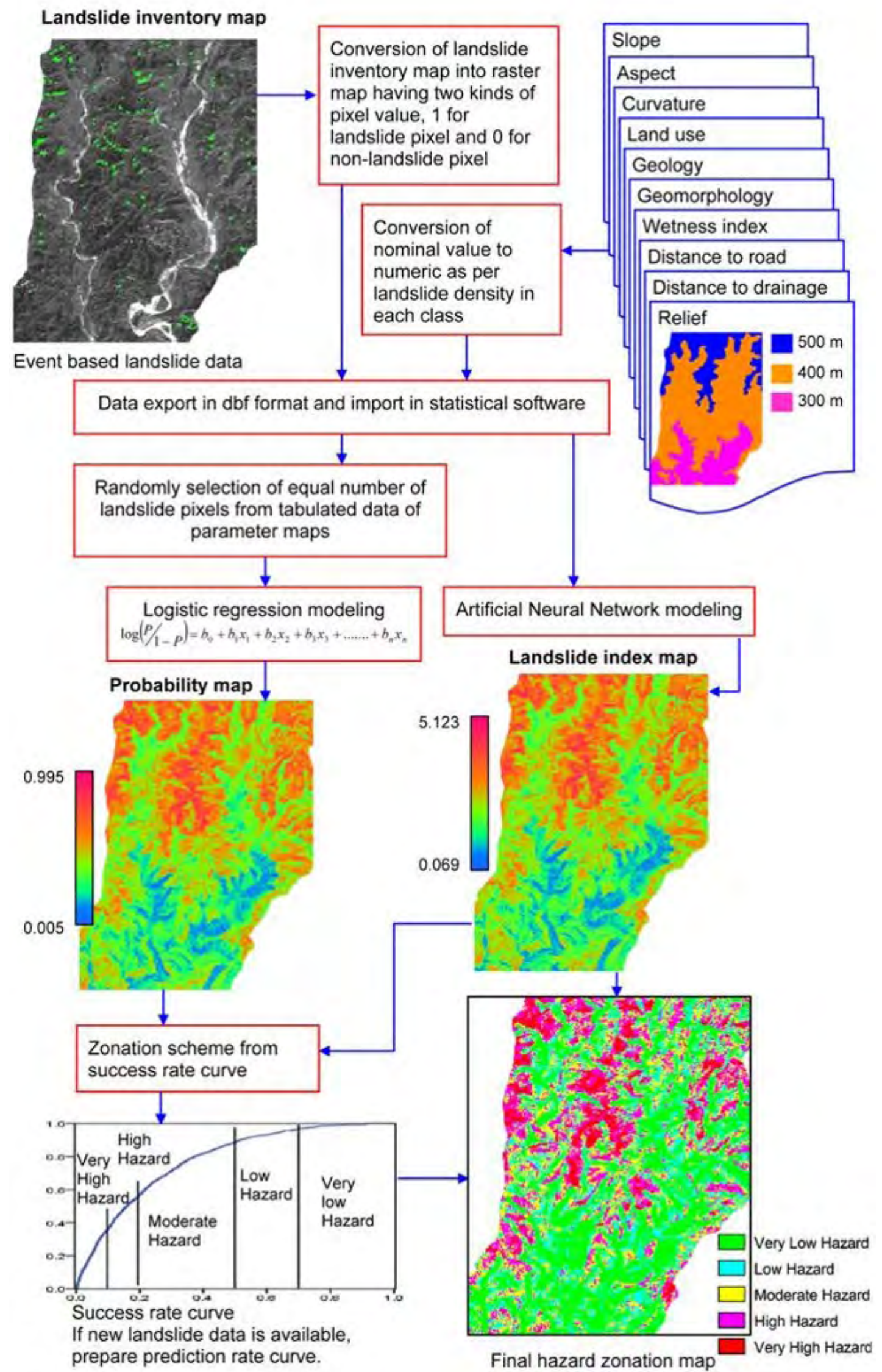

Fig. 4: Work flow of multivariate statistical analysis considering logistic regression and ANN methods. 
Dahal, R. K.

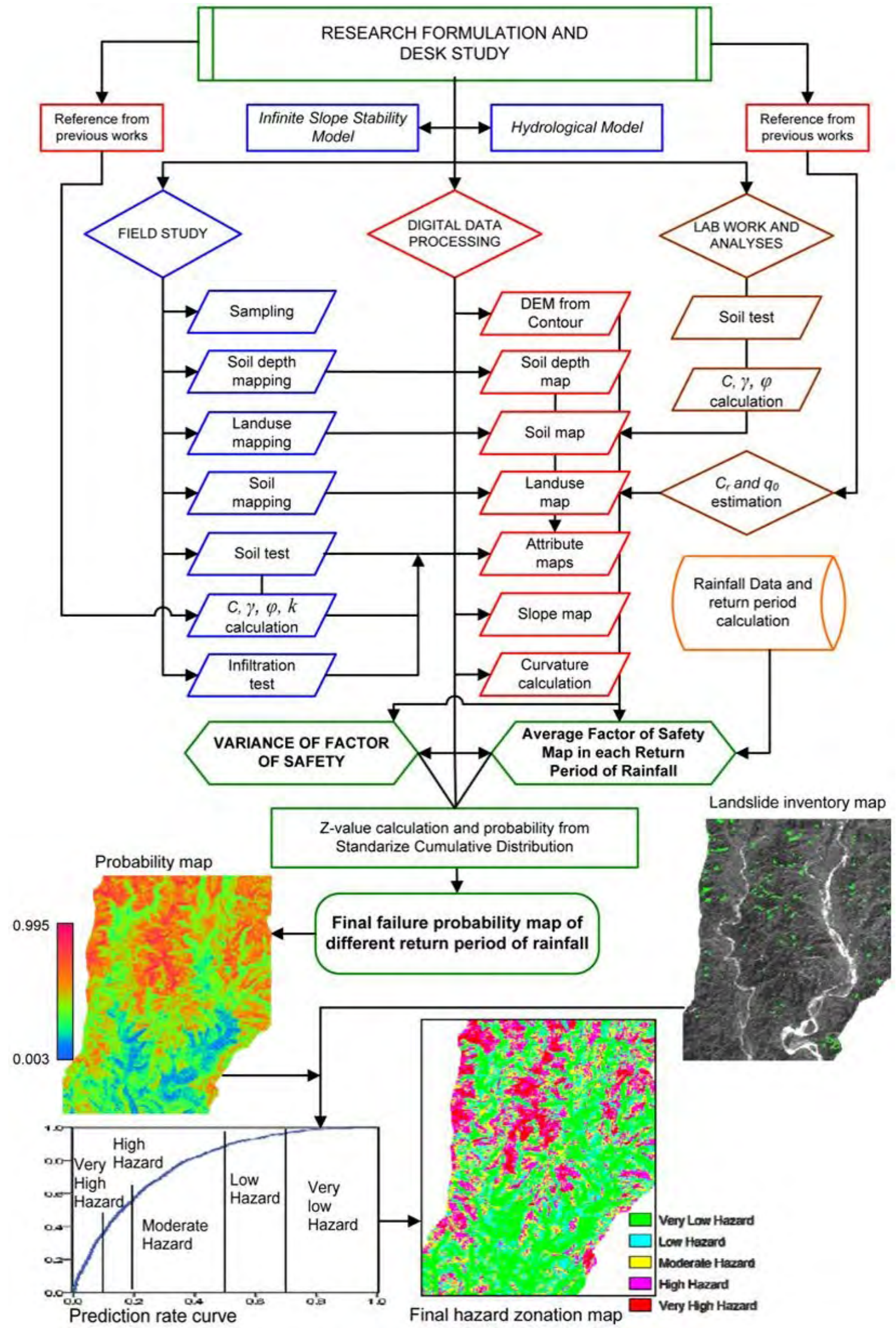

Fig. 5: Flow chart of deterministic landslide hazard analysis, $C$ is cohesion of soil, $\gamma$ is unit weight of soil, $\varphi$ is angle of internal friction of soil, $q 0$ surcharge load of plants, $\mathrm{k}$ is hydraulic conductivity (modified after Dahal et al. 2008c). 
Parameters in one catchment with landslide density

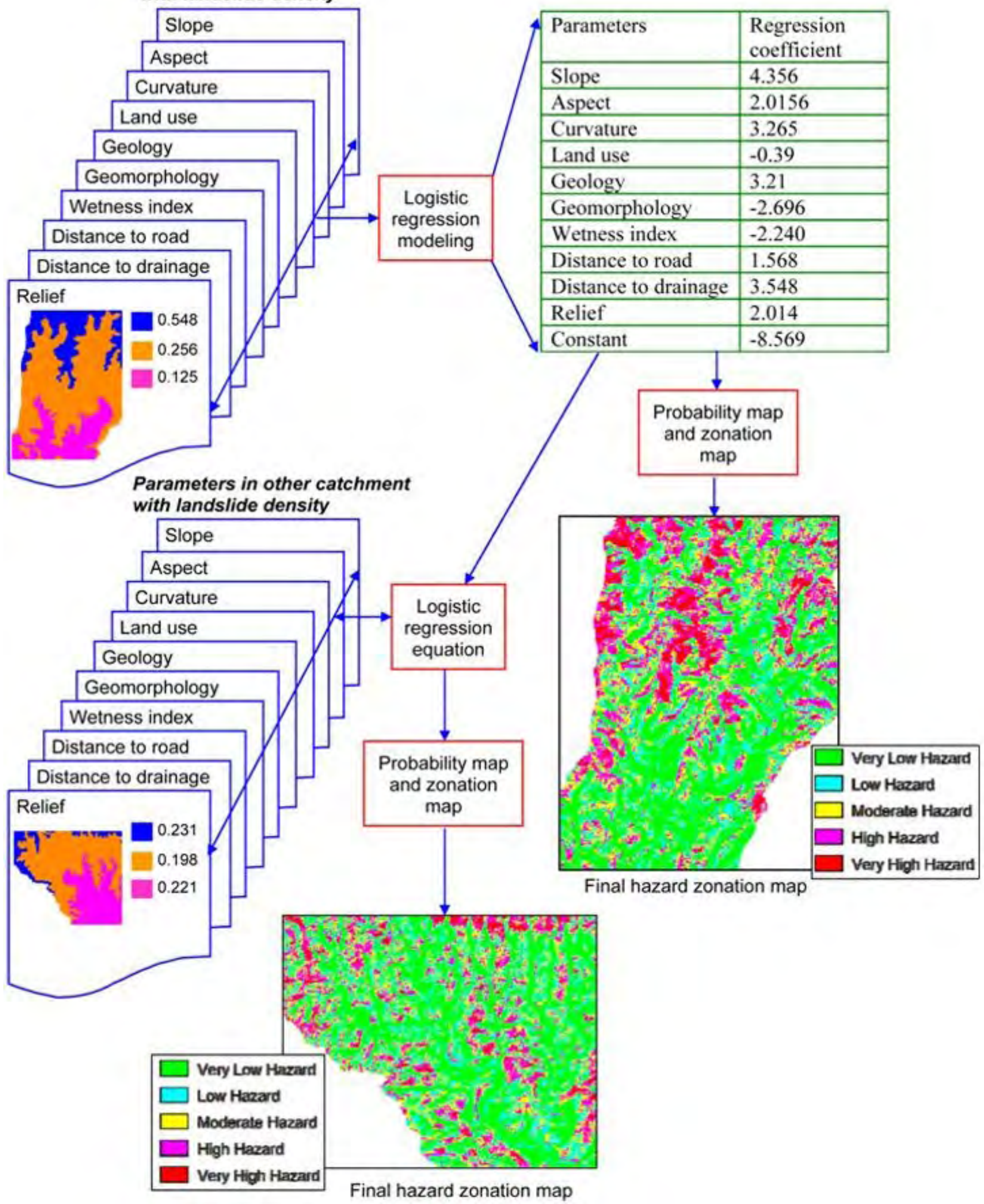

Fig. 6: Replication process of landslide hazard zonation mapping. 
the Kathmandu Valley, Lesser Himalaya, Nepal (Fig. 7). Geologically, the study area belongs to the Phulchauki and Bhimphedi consisting of intensely folded and faulted metasediments, mainly limestone with a subordinate amount of shale and sandstone of the Phulchauki Group (Fig. 8). The study area ranges in elevation from $1,400 \mathrm{~m}$ to $2,560 \mathrm{~m}$, with an factor class layer. InfoVal method is one of the familiar statistical methods of landslide hazard study in the Himalaya (Saha et al. 2005).

The weights-of-evidence method uses the Bayesian probability model, and was originally developed for mineral potential assessment (Bonham-Carter et al. 1988, 1989;

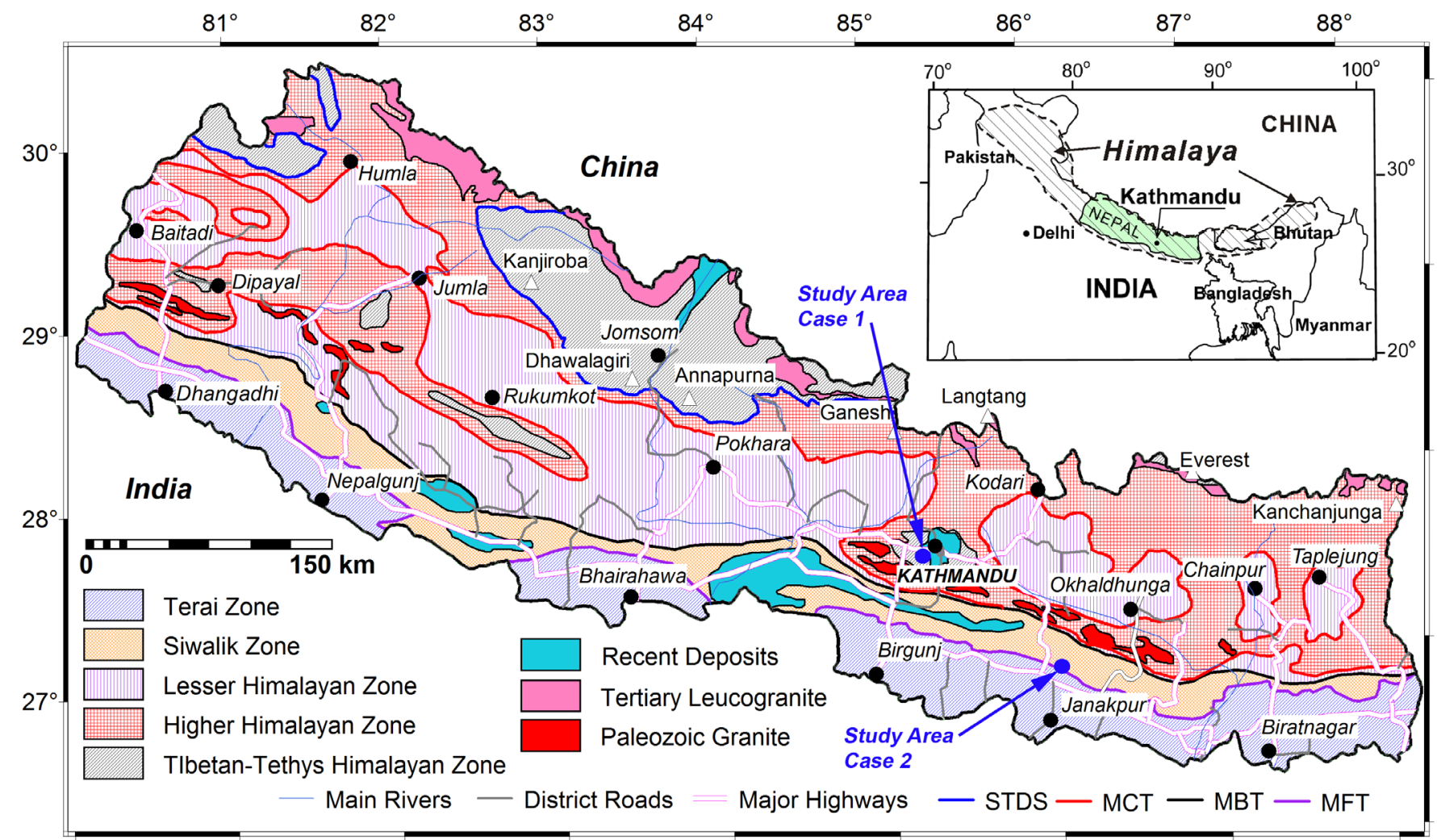

Fig. 7: Geological map of Nepal and location of the study area for Case 1 and Case 2.

area of $18.9 \mathrm{~km}^{2}$. The mean annual precipitation of area ranges from 1,500 to 2,200 $\mathrm{mm}$. Most of the slope faces north, and the slope gradient generally increases with increasing elevation. Colluvium is the main slope material above the bedrock. The area consists mainly of a dense forest of immature trees and thorny shrubs.

\section{InfoVal and WoE methods}

In this study, information value and weights-of-evidence methods were used for the landslide hazard mapping. Information Value (InfoVal) method considers the probability of landslide occurrence within a certain area of each class of a landslide causative factor. This method is also regarded as the simplification of the method described by Yin and Yan (1988), in which the weights of a particular class in a causative factor are determined as follow.

$$
W_{\mathrm{i}}=\log _{\mathrm{e}}\left\{\frac{D_{\text {clas }}}{D_{\text {map }}}\right\} \text {. }
$$

Where, Wi is the weight given to the all class of a particular landslide causative factor layer, Dclas is the landslide density within the landslide causative factor class, and Dmap is sum of the landslide density within the entire landslide causative
Agterberg 1992; Agterberg et al. 1993; Bonham-Carter 2002). This method has also been applied to landslide susceptibility mapping (Lee et al. 2002; Van Westen et al. 2003, Lee and Choi 2004, Lee and Sambath 2006; Dahal et al. 2008a,b; Sharma and Kumar 2008; Neuhäuser and Terhorst 2007). A detailed description of the mathematical formulation of the method is available in Bonham-Carter (2002). The method calculates the weight for each landslide causative factor based on the presence or absence of the landslides within the area. The method calculates the weight for each landslide predictive factor (F) based on the presence or absence of the landslides (L) within the area, as indicated in Bonham-Carter (2002) as follow.

$$
\begin{aligned}
& W_{\mathrm{i}}^{+}=\log _{\mathrm{e}} \frac{P\{F \mid L\}}{P\{F \mid \bar{L}\}} . \\
& W_{\mathrm{i}}^{-}=\log _{\mathrm{e}} \frac{P\{\bar{F} \mid L\}}{P\{\bar{F} \mid \bar{L}\}} .
\end{aligned}
$$

Where, $\mathrm{P}$ is probability and loge is the natural logarithm. Similarly, $F$ is presence of potential landslide predictive factor, is absence of a potential landslide predictive factor, $\mathrm{L}$ is presence of landslide, and is absence of a landslide. A positive weight $(\mathrm{Wi}+)$ indicates that the causative factor is present at 


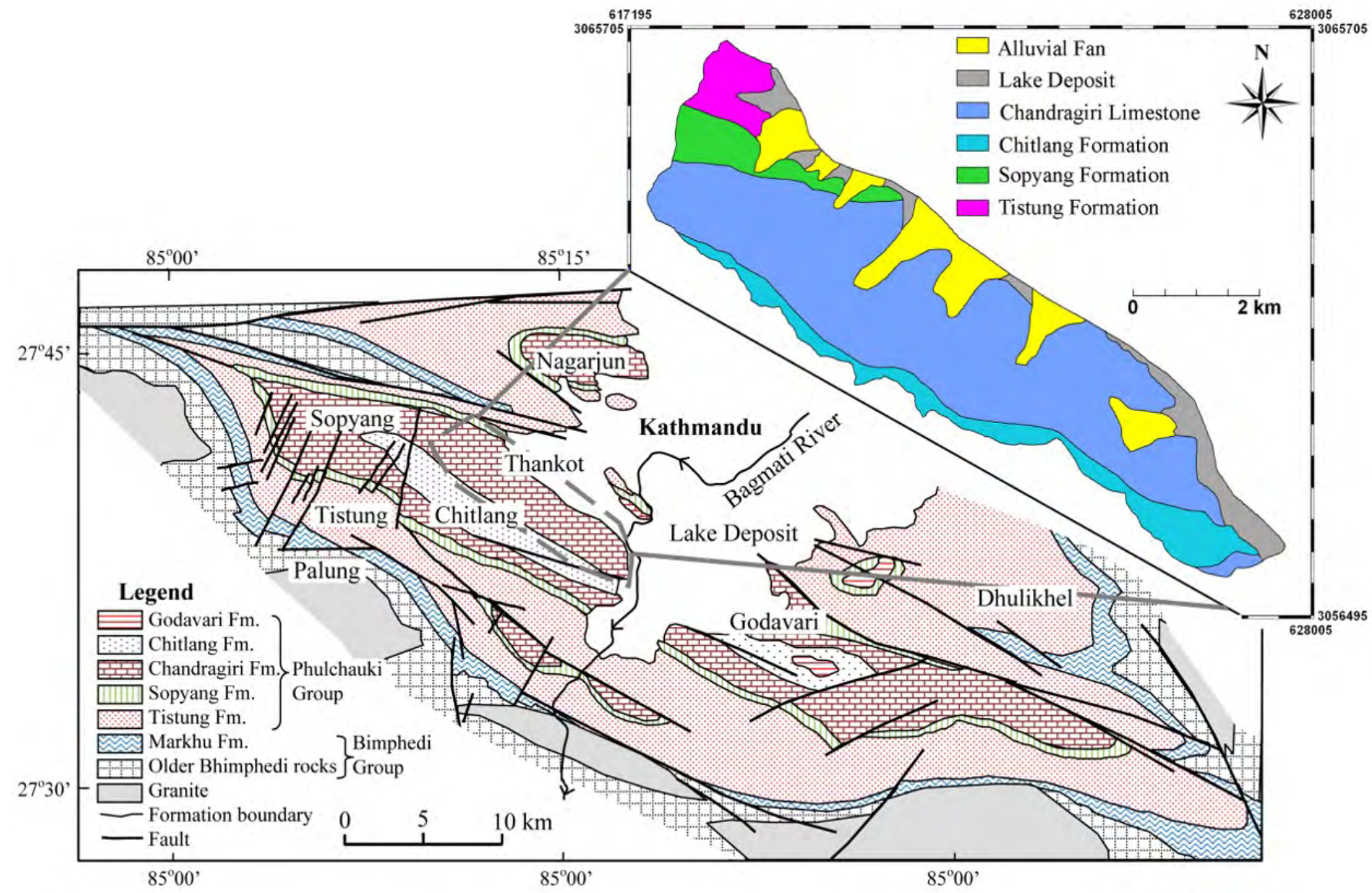

Fig. 8: Geological map of south of Kathmandu valley (modified after Stöcklin and Bhattarai 1977) and geological map of study area is shown in inset.

the landslide location, and the magnitude of this weight is an indication of the positive correlation between presence of the causative factor and landslides. A negative weight (Wi) indicates an absence of the causative factor and shows the level of negative correlation. The difference between the two weights is known as the weight contrast, Wfi (Wfi $=\mathrm{Wi+-}$ $\mathrm{Wi}-)$ and the magnitude of contrast reflects the overall spatial association between the causative factor and landslides. The suffix ' $i$ ' represents causative factor. In weights-of-evidence method, the combination of causative factors assumes that the factors are conditionally independent of one another with respect to the landslides (Bonham-Carter 2002; Lee and Choi 2004).

Debris slide and debris flow (Varnes 1984) types of landslide have occurred predominantly in the study area. In this study, only debris slide scars were considered, because InfoVal and WoE can only be applied for single types of landslides. All the debris flows in the area were initiated after failure at the upper reaches of topographic hollows. Thus, debris slides were the prime landslide consequence for the study area after rainfall events, and this study deals with landslide hazard associated with the areas prone to landslide initiation.

\section{Data preparation}

The main steps for landslide hazard mapping were data collection and the construction of a spatial database from which relevant factors were extracted. This was followed by assessment of the landslide hazard using the relationship between landslide and landslide causative factors, and the subsequent validation of results. For the hazard analysis, a number of thematic data of causative factors were identified, including slope, slope aspect, geology, flow accumulation, relief, landuse, soil type, soil depth, distance to road, and mean annual rainfall. Topographic maps and aerial photographs acquired from Department of Survey, Government of Nepal were considered as basic data sources for generating these layers. Field surveys were carried out for data collection and to prepare data layers of various factors, as well as to prepare geological, soil depth, soil type and landuse maps. A landslide distribution map after the 2002 extreme monsoon rainfall events was also prepared in field. These data sources were used to generate various data layers using the GIS software ILWIS 3.3.

A landslide inventory map is the simplest output of direct landslide mapping. It shows the location of discernible landslides. It is a key factor used in landslide hazard mapping by InfoVal and WoE methods because the overlay analysis requires an inventory map. Two landslide inventory maps for new and older landslides were prepared (Fig. 9). For the new landslide inventory map, landslides occurring after the 2002 rainfall events were recorded in field immediately after the events, and the landslide inventory map was prepared. As 
a consequence of 2002 extreme rainfall events, a total of 73 debris slide scars were detected in the study area. For the older landslide maps, aerial photographs from 1979, 1989 and 1995 at scales of 1:25000 and 1:15000 were taken as a data source. Landslide scars were identified with stereoscopes, and the GIS data layer was prepared. Similarly, for 1:15000 scale aerial photographs, epipolar stereo pairs were generated in ILWIS 3.3 and landslide inventory maps were prepared from screen digitization. A total of 119 landslide scars were delineated from the 1979, 1989, and 1995 photos. Rainfall data from the nearest rainfall station suggested that there were comparatively high monsoon rainfall events in 1978, 1979, 1987, 1988, and 1993. These events might be responsible for triggering these old landslides. For the geological data layer preparation, previous studies (Stöcklin and Bhattarai 1977; Acharya 2001) were consulted and geological boundaries of formations were checked and modified as per the field observations. A Digital Elevation Model (DEM) having $10 \mathrm{~m} \times 10 \mathrm{~m}$ pixel size is used to generate various geomorphological parameters which influence the landslide activity in an area. From this DEM, geomorphological thematic data layers such as slope, aspect and relative relief, distance to drainage, and flow accumulation were prepared. The relative relief data layer was prepared from the difference in maximum $(2500 \mathrm{~m})$ and minimum elevation $(1,400 \mathrm{~m})$ and was sliced into twelve classes at $100 \mathrm{~m}$ bin.

Landuse is also one of the key factors responsible for the occurrence of landslides, since barren slopes are more prone to landslides. The landuse map was prepared in the field on a topographical map at 1:25,000 scale. Subsequently, the landuse data layer was generated as vector polygons and converted to a raster landuse map in GIS. Road construction activity is another controlling factor for the stability of slopes. Thus, a distance to road factor map was also prepared for analysis. Soil mapping was performed mainly for estimating soil depth and identifying engineering soil types. The study of landslides after the 2002 extreme rainfall events suggested mainly soil depths of $0.5 \mathrm{~m}$ to $2 \mathrm{~m}$ had maximum susceptibility to failure. The maps of soil depth and engineering soil types (silty gravel, low plastic clay, silty sand and clayey to silty gravel) were also prepared.

Rainfall is an extrinsic variable in hazard analysis, and the spatial distribution of mean annual rainfall is commonly used in statistical hazard analysis. But, the study area has many landslides triggered by extreme rainfall. Thus, to make this research more practical, extreme one day rainfall, for 11 stations around Kathmandu valley was used to prepare an extreme one day rainfall map. Thus, a total of 11 factors maps (slope, aspect, relief, flow accumulation, soil depth, engineering soil type, geology, land use, distance to drainage, distance to road and extreme one day rainfall) were selected as thematic data layers for analysis.

\section{Analysis and Results}

To evaluate the contribution of each causative factor to landslide hazard, both new and old landslide distribution data layers were compared separately with various thematic data

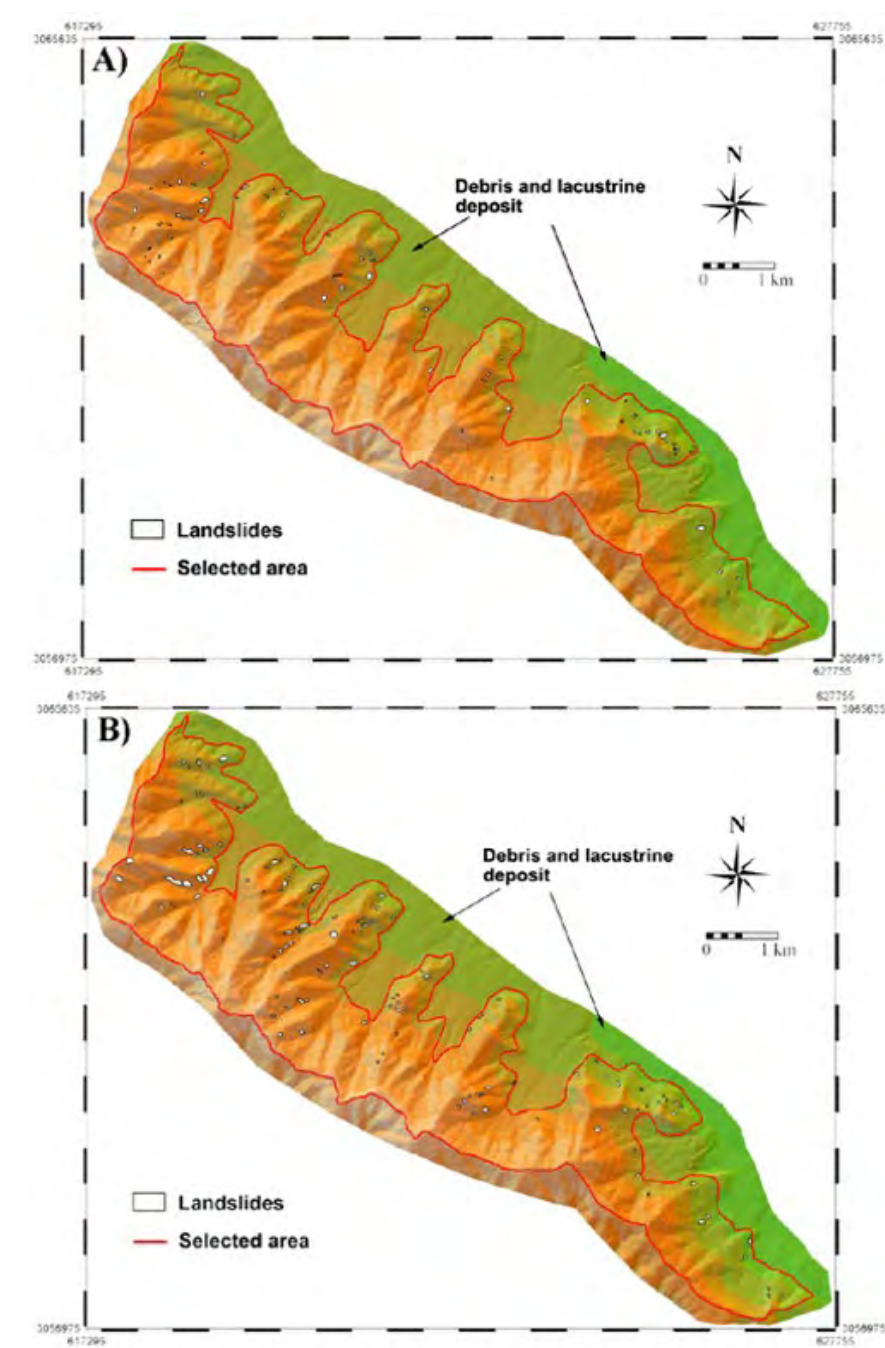

Fig. 9: Landslide inventory maps of the study area, A) Inventory map prepared after $\mathbf{2 0 0 2}$ extreme rainfall event, B) Inventory map prepared from aerial photographs of 1979, 1989, and 1995.

layers. For this purpose, Eq. (1) of InfoVal method was written according to numbers of pixels as follows.

$$
W_{\mathrm{i}}=\log _{\mathrm{e}}\left(\frac{N p i x_{\mathrm{a}}}{N p i x_{\mathrm{b}}} / \frac{\sum N p i x_{\mathrm{a}}}{\sum N p i x_{\mathrm{b}}}\right)
$$

Where, $\mathrm{W}_{\mathrm{i}}$ is the weight given to a certain parameter class (such as, a rock type or slope class). Npix a number of pixels which contain landslides, in a certain parameter class. $N p i x_{\mathrm{b}}$ is total number of pixels in a certain class in a causative factor. The natural logarithm is used to take care of the large variation in the weights. Similarly, For WoE method, Eqs. (2), and (3) were also written according to numbers of pixels.

$$
\begin{aligned}
& \text { Npix } \\
& W_{\mathrm{i}}^{+}=\log _{\mathrm{e}} \frac{\frac{N p i x_{1}+N p i x_{2}}{N p i x_{3}}}{N p i x_{3}+N p i x_{4}} \\
& N_{p i x_{2}} \\
& W_{\mathrm{i}}^{-}=\log _{\mathrm{e}} \frac{\frac{}{N p i x_{1}+N p i x_{2}}}{\frac{N p i x_{4}}{N p i x_{3}+N p i x_{4}}}
\end{aligned}
$$


Where, Npix $x_{1}$ is the number of pixels representing the presence of both a causative factor and landslides; Npix 2 is the number of pixels representing the presence of landslides and absence of a causative factor; Npix 3 is the number of pixels representing the presence of a causative factor and absence of landslides; Npix ${ }_{4}$ is the number of pixels representing the absence of both a causative factor and landslides.

All thematic maps were stored in raster format with a pixel size of $10 \mathrm{~m} \times 10 \mathrm{~m}$ and were combined with three landslide inventory maps (new landslides, old landslides and all landslides) separately for the calculation of the weights with InfoVal method and positive and negative weights with $\mathrm{WoE}$ method. The calculation procedure was written in the form of a script file in ILWIS 3.3, (Table 1 and Table 2) consisting of a series of GIS command to support Eqs. (4), (5) and (6). The resulting total weights directly indicate the importance of each factor. If the total weight is positive, the factor is favourable for the occurrence of landslides, and if it is negative, it is not favourable. The weights are assigned to the classes of each thematic layer, to produce weighted thematic maps, which are overlaid and numerically added according to Eq. (7) for InfoVal method and Eq. (8) for WoE method to produce Landslide Hazard Index (LHI) maps.

$$
\begin{aligned}
& W_{\mathrm{ij}}=\mathrm{W}_{\text {Slope }}+\mathrm{W}_{\text {Aspcls }}+\mathrm{W}_{\mathrm{FA}} \\
& +\mathrm{W}_{\text {Relief }}+\mathrm{W}_{\text {Disdrn }}+\mathrm{W}_{\text {Depth }} \\
& +\mathrm{W}_{\text {Egsoil }}+\mathrm{W}_{\mathrm{Geo}}+\mathrm{W}_{\text {Landuse }} \\
& +\mathrm{W}_{\text {Disrd }}+\mathrm{W}_{\text {Rnfall }} \\
& W_{\text {fij }}=\mathrm{W}_{\text {fllope }}+\mathrm{W}_{\text {fAspcls }}+\mathrm{W}_{\text {fFA }} \\
& +\mathrm{W}_{\text {fRelief }}+\mathrm{W}_{\mathrm{fDisdrn}}+\mathrm{W}_{\text {fDepth }} \\
& +\mathrm{W}_{\mathrm{fEgsoil}}+\mathrm{W}_{\mathrm{fGeo}}+\mathrm{W}_{\mathrm{fLanduse}} \\
& +\mathrm{W}_{\mathrm{fDisrd}}+\mathrm{W}_{\mathrm{f} \text { Rnfall }}
\end{aligned}
$$

Where, $\mathrm{W}_{\text {Slope }}$ and $\mathrm{W}_{\text {fSlope }}, \mathrm{W}_{\text {Aspcls }}$ and $\mathrm{W}_{\text {fAspcls }}, \mathrm{W}_{\mathrm{FA}}$ and $\mathrm{W}_{\text {fFA }}$, $\mathrm{W}_{\text {Relief }}$ and $\mathrm{W}_{\text {fRelief }}, \mathrm{W}_{\text {Disdrn }}$ and $\mathrm{W}_{\text {fDisdrn }}, \mathrm{W}_{\text {Depth }}$ and $\mathrm{W}_{\text {fDepth, }}, \mathrm{W}_{\text {Egsoil }}$ and $\mathrm{W}_{\text {fEgsoil }}, \mathrm{W}_{\text {Geo }}$ and $\mathrm{W}_{\text {fGeo }}, \mathrm{W}_{\text {Landuse }}$ and $\mathrm{W}_{\text {fLanduse }}, \mathrm{W}_{\text {Disrd }}$ and $\mathrm{W}_{\mathrm{fDisrd}}$, and $\mathrm{W}_{\text {Rnfall }}^{\text {Geo }}$ and $\mathrm{W}_{\mathrm{fR} \text { freall }}$ are distribution-derived weights of slope, slope aspect, flow accumulation, relief, distance to drainages, engineering soil type, geology, landuse, distance to roads, and extreme one day rainfall factor maps, for InfoVal and WoE methods, respectively. The suffix ' $j$ ' in Eqs. (7) and (8) represents a class in the causative factors.

Three attribute maps of different landslide cases were prepared from respective LHI values. With InfoVal method, LHI values were found to lie in the range from -29.774 to 7.097 for the new landslides case, -15.916 to 5.510 for the old landslide case, and -16.654 to 5.692 for the all landslide case. Likewise, with WoE method, LHI values were found in -15.662 to 8.231 for the new landslides case, -12.483 to 6.769 for the old landslides case, and -13.023 to 6.926 for the case of all landslides. The ability of LHI values to predict landslide occurrences was verified using the success rate curve (Chung and Fabbri 1999), prediction rate and effect analysis (Van Westen et al. 2003; Lee 2004; Dahal et al. 2008a). The success rate indicates what percentage of all landslides occurs in the classes with the highest value of susceptibility. When old landslides are used for LHI value calculation and new landslides are used for prediction, the calculated accuracy rate is called prediction rate (Van Westen et al. 2003; Lee et al. 2007) and is most suitable parameter for independent validation of the LHI values. Effect analysis helps to validate and to check the predictive power of selected factors that are used in hazard analysis.

\section{Success rates and effect analyses}

The success rate curves of all three maps are shown in Fig. 10. These curves are measures of goodness of fit. To obtain the success rate curve for each LHI map, the calculated landslide index values of all pixels in the maps were sorted in descending order. Then the pixel values in descending order (maximum to minimum LHI value) were categorized into 100 classes with $1 \%$ intervals. The class domain having 100 class groups and covering high to low LHI value were prepared and classified LHI maps were prepared with the slicing operation in ILWIS 3.3. These classified LHI maps (having 100 class groups) were crossed with the landslide inventory map. Number of landslide pixels in each class group (from 1\% to $100 \%$ ) was obtained from cross table value. Then, the success rate curves for both methods were created by plotting class group (from $1 \%$ to $100 \%$ ) in $\mathrm{x}$-axis and respective value of landslide pixel percentage in each class group in y-axis. Fig 10A represents success rate of InfoVal method and Fig 10B represent success rate of WoE method for new landslides, old landslides and all landslides cases. When InfoVal method was evaluated for success rate, in the case of new landslides, the success rate reveals that $10 \%$ of the study area where the LHI had a higher rank could explain $50 \%$ of total new landslides in $10 \%$ of hazard class. Likewise, $30 \%$ of higher LHI value could explain $89 \%$ of all landslides in $30 \%$ of hazard class. Similarly, for the cases of old landslides and all landslides, $30 \%$ high LHI value could explain about $78 \%$ of total landslides in $30 \%$ of hazard class.

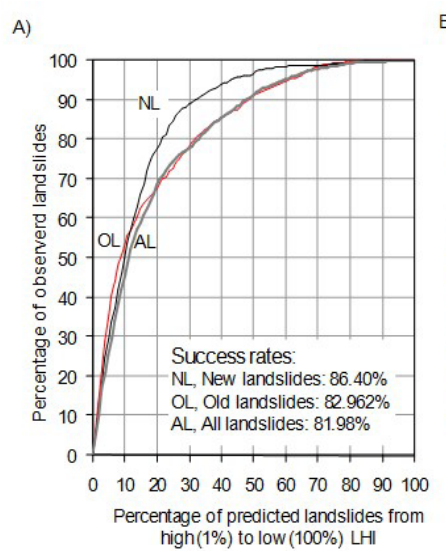

B)

Fig. 10: (A) Success rate curves of landslide hazard values calculated with InfoVal method and, (B) WoE method. The areas under the curve for all three cases were determined considering a total area under the curve as $100 \times 100=10$, 000 units. Other details are in text. 
Table 1: Script for weights of evidence method to use in Ilwis 3.3.

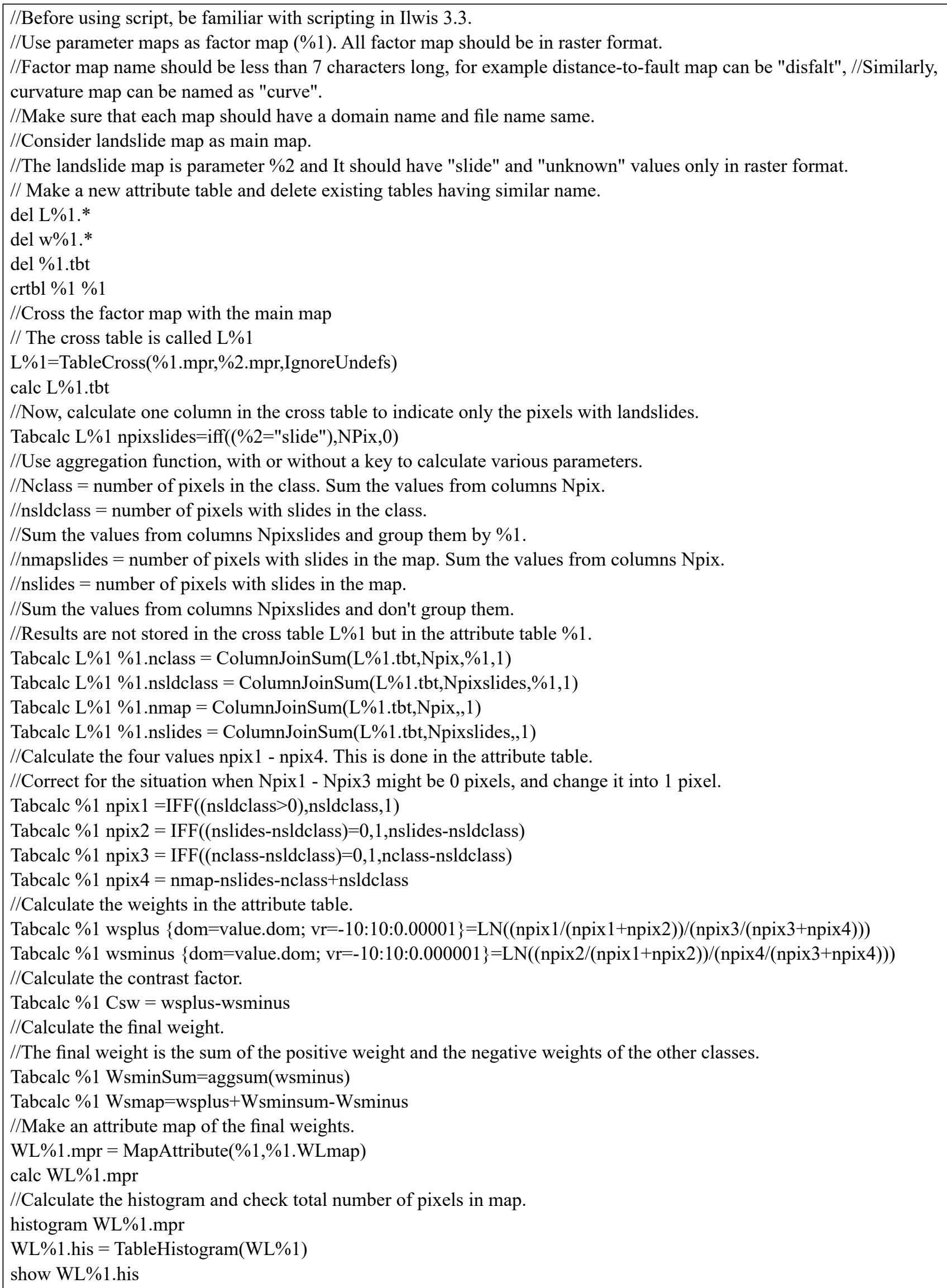


Table 2: Script for Information value method to use in Ilwis 3.3.

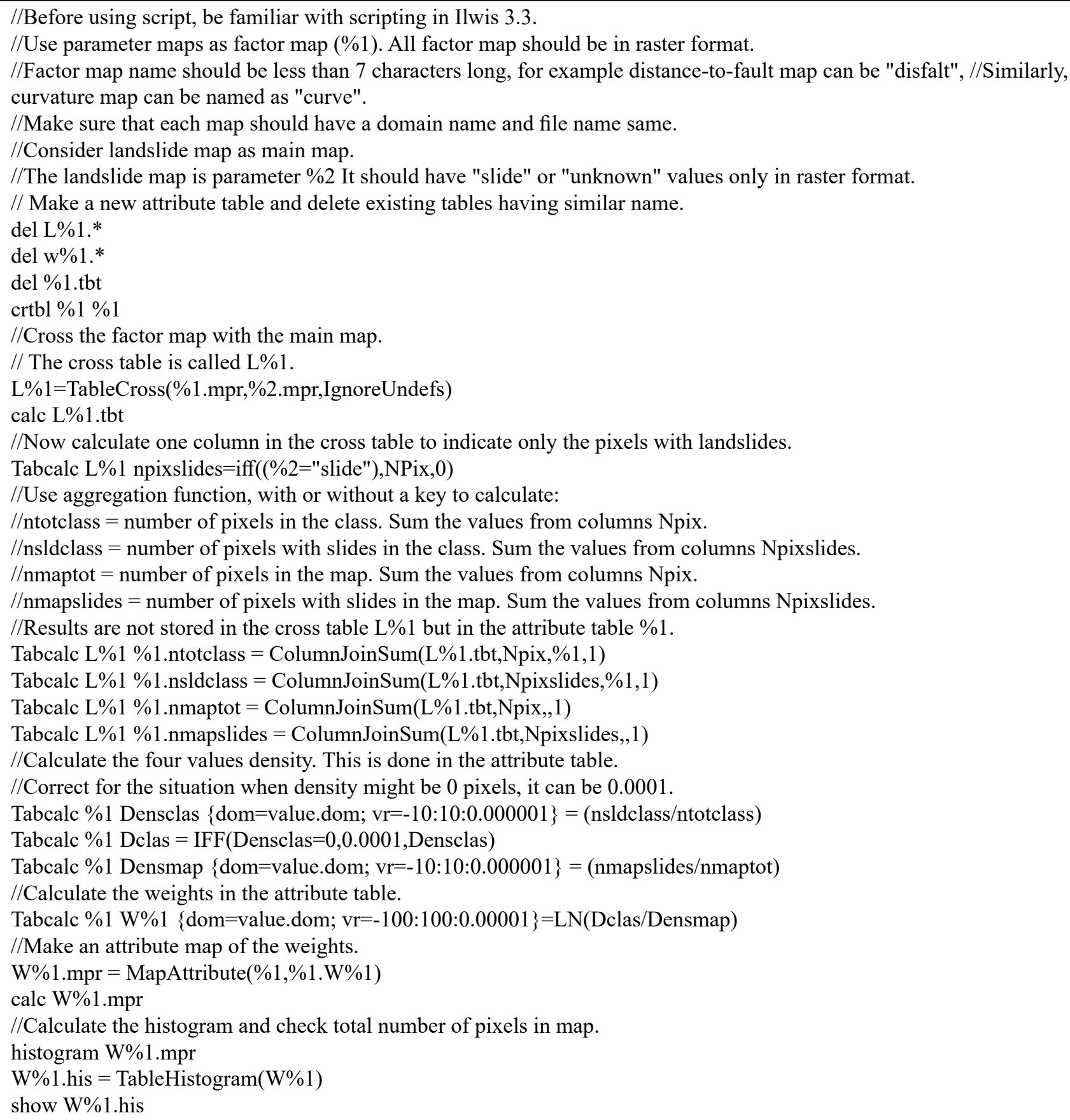

Similarly, When WoE method was concerned, in the case of new landslides, the success rate reveals that $10 \%$ of the study area where the LHI had a higher rank could explain $50 \%$ of total new landslides in $10 \%$ of hazard class. Moreover, $30 \%$ of higher LHI value could explain $88 \%$ of all landslides in $30 \%$ of hazard class. Likewise, for the cases of old landslides and all landslides, 30\% high LHI value could explain about $80 \%$ of total landslides in $30 \%$ of hazard class. The area under the curve qualitatively measures the success rate of LHI value. A total area equal to one denotes perfect prediction accuracy. Similarly, when the area under the curve is less than 0.5000 , the model is invalid. In this study, area under the curves with
InfoVal method ranged from 0.8198 to 0.8640 . Likewise, area under the curves with WoE method ranged from 0.8213 to 0.8595 . This implies that the success rate of InfoVal and WoE methods are more or less same. Analysis of the new landslide case shows a higher value of success rate than other two cases. Fig. 11 represents prediction rate of InfoVal and WoE methods. InfoVal method has prediction rate $78.6 \%$ whereas WoE has prediction rate $79.5 \%$. As mentioned in earlier section, prediction rate is independent test of hazard map accuracy and this study suggests that both methods have quite acceptable accuracy. Effect analyses were also done to understand the predictive power of factor maps used 
in analysis. Total five combinations of geomorphology-, geology- and human interventions-related factors were used in effect analysis. Combinations of only geomorphologyrelated factors, geomorphology and geology-related factors, and geomorphology and human intervention-related factors revealed higher success rates in both methods.

\section{Hazard zonation map}

For the purpose of hazard zonation maps, reference to prediction rate curves (see Fig. 11) was made and corresponding values of LHI in classes 30\%, 50\%, 70\% and 90\% LHI value were selected for hazard classification. Total five landslide hazard classes, very low (less than $30 \%$ class of low to high LHI value), low (30\% - 50\% class of low to high LHI value), moderate $(50 \%-70 \%$ class of low to high LHI value), high ( $70 \%-90 \%$ class of low to high LHI value), and very high (more than $90 \%$ class of low to high LHI value, i.e., most higher LHI values) were established. On the basis of 30\%, $50 \%, 70 \%$ and $90 \%$ of low to high LHI value calculated from both methods, two classified hazard maps were prepared for LHI values of new landslides and illustrated in Fig. 12A and 12B. New landslide case is considered for final hazard maps preparation, because it has high success rate (see Fig. 10).

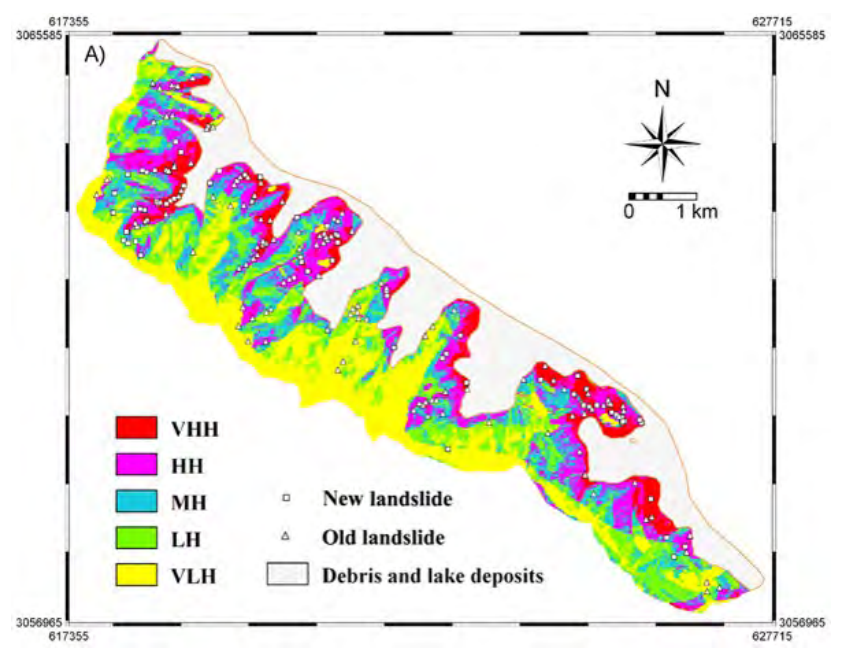

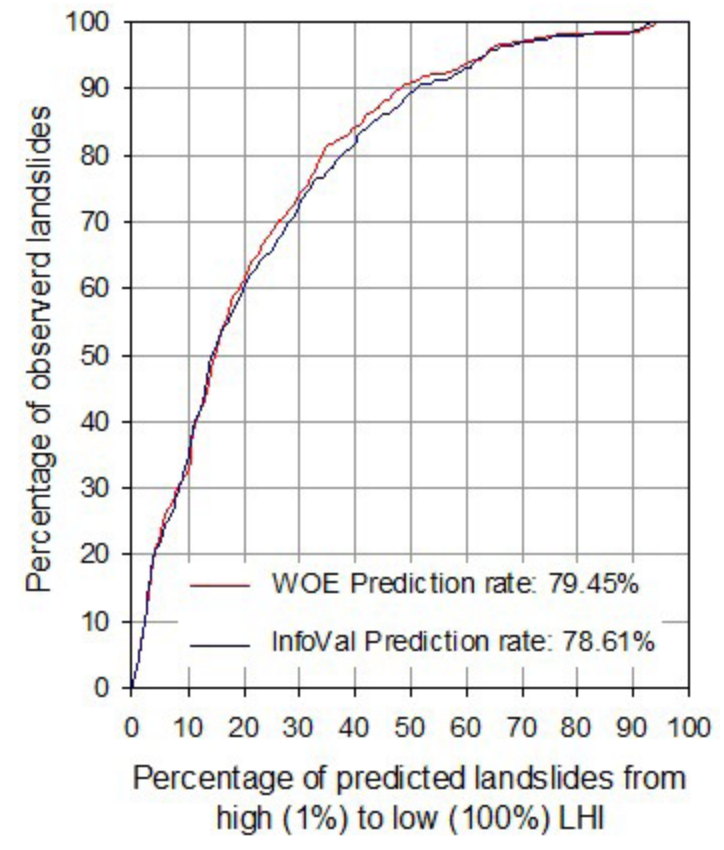

Fig. 11: Prediction rate curves of landslide hazard values calculated from old landslide inventory maps in InfoVal method and similar prediction rate for WoE method.

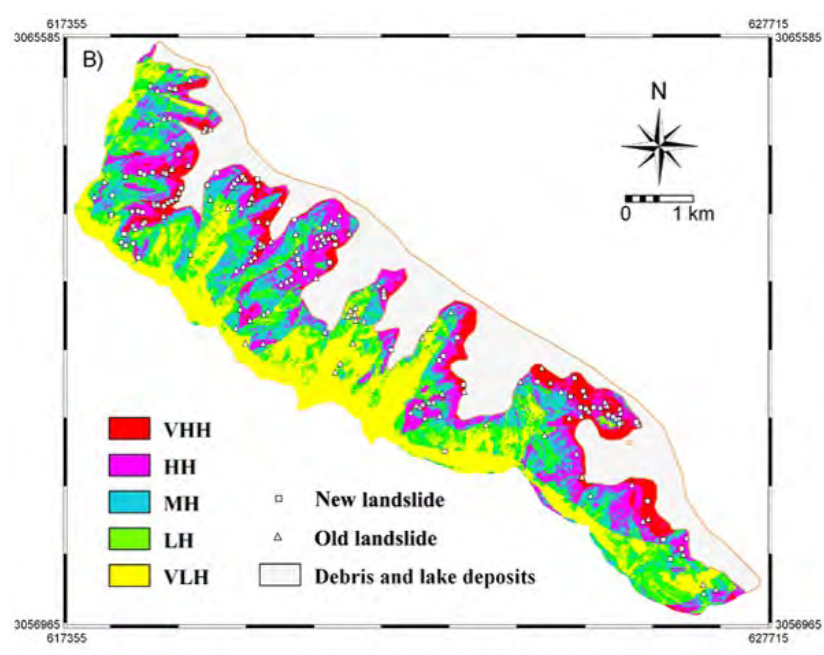

Fig. 12: Classified landslide hazard map of the south-western hills of Kathmandu valley after A) InfoVal method and B) WoE method.

\section{Case 2 - Multivariate Landslide hazard mapping}

\section{Study area}

The study area is located in the south-eastern hills of the Nepal Himalaya and belongs to the Sub Himalaya Zone or Siwalik (see Fig. 7) of the Himalaya. Siwalik, also called as Churia in Nepal, is the youngest low-altitude mountain in the Himalayan chain. The average slope and relief of terrain are high in the western regions compared to other regions of Nepal. Many parts of the Siwalik are inhabited by relatively large human population with agriculture and livestock as the mainstays of livelihood. River valleys, comprised of narrow tracts of flatland, are extensively used for cultivation and settlement. The population and livelihood activities are highly vulnerable to floods, debris torrents, debris slides and debris flows from hill-slopes. Obviously, the pressure of the population and fast-growing development and economic activities on forest and cultivation is high in the entire Siwalik. Land use and land cover distribution pattern shows the predominance of forest in the hill slopes and cultivated land in the plain area. Considerable patches of cultivated areas also lie on areas of steep topography, flood and slope failure-prone areas. Over the last four decades there has been a tremendous change in land use and land cover, but this change has been less in the last decade (Ghimire et al. 2008) because of the conversion of forest areas into cultivated lands. The change was more pronounced in slopes of Siwalik and inner river valleys. A significant expansion of cultivated land in steep slopes and in 
flood prone areas clearly indicates environmental degradation and livelihood vulnerability in the Siwalik (Ghimire et al. 2008).

Two typical catchments viz. Charnath and Jalad (Fig. 13) are selected for the study. Both catchments are located in the northern part of Dhanusa district of Nepal (Fig. 2). The Jalad and Charnath are two major river systems originating from the Siwalik and they are highly disastrous rivers. These catchments have very fragile lithology and steep topography, predisposing the landscape to have significant problems of geology and geomorphology related slope failures. The Charnath River is about $8 \mathrm{~km}$ east from the outlets of the Jalad River in Terai. Jalad catchment in Churia is north-south elongated where as Charnath is northwest-southeast elongated.

\section{Geological and geomorphological settings}

The study area belongs to the Siwalik Zones. The Siwalik is made up of geologically very young sedimentary rocks such as mudstones, shale, sandstones, siltstones and conglomerates. These rocks are soft, unconsolidated and easily disintegrable. According to three-fold classifications of Siwalik, it can be divided into three geological units (Burbank et al. 1996; Ulak and Nakayama 1999), Lower Siwalik, Middle Siwalik and Upper Siwalik as per the occurrence of rock types. Lower Siwalik usually has thin to thickly bedded green to grey coloured mudstone and siltstone, whereas Middle Siwalik has thick to very thickly bedded sandstone. The Upper Siwalik contains thick beds of loose and fragile conglomerates.

Factors such as the excessive rainfall and human intervention are the main triggering agents of landslides in Siwalik. The factors like, groundwater condition, river under cutting and deforestation on slopes are also facilitating slope failures. Similarly, Lower Siwalik and Middle Siwalik have problem from alternating beds of mudstones and sandstone. In such alternating bands, mudstone can flow when saturated with water, which results overhanging sandstone beds. Such overhang jointed sandstone beds are easily disintegrated into blocks. Similarly, throughout Nepal, the rainfall within the Siwalik is normally in the range of 2000 to $2500 \mathrm{~mm}$ per year (Ghimire et al. 2008). As a result, geological conditions and the climate render the Siwalik highly susceptible for landslides. In the both Jalad and Charnath catchments, the Siwalik can be divided into two units: Middle Siwalik and Upper Siwalik on the basis of lithological composition. The Middle Siwalik consists of alternation of thickly bedded light yellow to light grey coloured mudstone and light grey coloured sandstone with subordinate pebbles. The proportion of sandstone and mudstone is equal on the southern part, while the proportion of sandstone increases towards upstream of both catchment.

Land degradation is a common problem in fragile and steep hill slopes of both catchments, where pressure from human intervention and grazing animal are extensively high. All transport routes are terribly used only for smuggling wood from forest. As a result, vicinity of the routes are

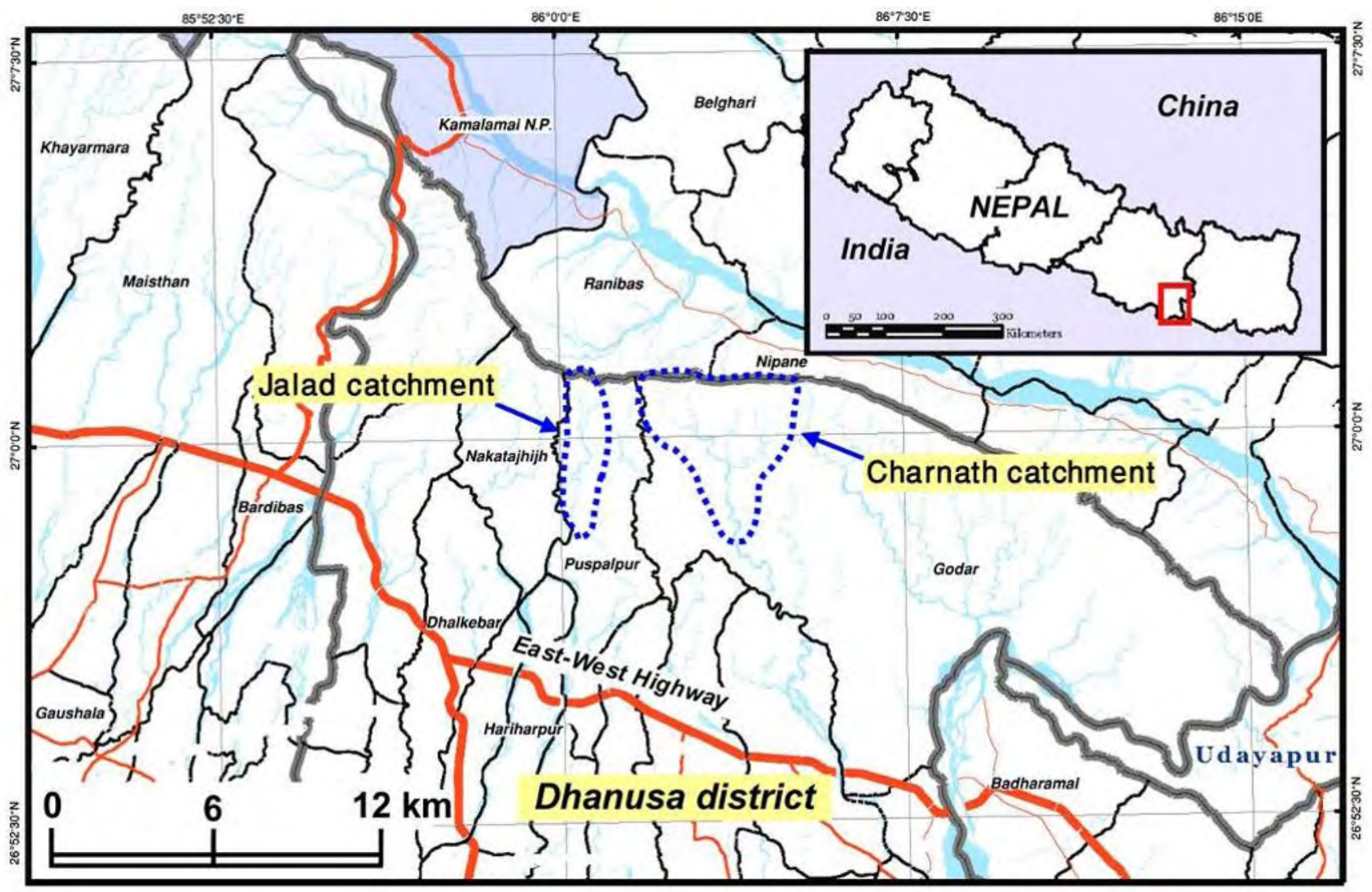

Fig. 13: Location map of Jalad and Charnath catchments (map modified from UNDP 2010). 
exceedingly deforested. Debris slides and debris flows are the major land degradation processes in the both catchments. Charnath catchment is relatively densely populated than the Jalad catchment. In Nepal, landless population is high in the northern Lesser Himalayan Zone and migration to the southern Siwalik Range is a common problem. Both catchments have same problem of migration and improper agricultural practices make both catchments highly vulnerable to landslides.

The stream channels are narrowed and meandered showing cliffs formed by bank cuttings on their concave banks. The river width is relatively higher in upstream than downstream. The sediment thickness of channel lag on the riverbed is not more than $10 \mathrm{~m}$, while in some places, the river flows over the bedrock. Main geological difference in Jalad and Charnath is on the coverage of Upper Siwalik (loose conglomerate). The nearly half portion of Jalad catchment has Upper Siwalik where as Charnath has Upper Siwalik only in upper reaches. As a result, there are fewer amounts of gravels in Charnath river bed in comparison to the Jalad river bed.

\section{Logistic regression model}

In this study, logistic regression model was used to assess landslide hazard indexes. Logistic regression can be used to determine the relation of landslide occurrence and the related factors (Guzzetti et al. 1999; Dai and Lee 2002; Ohlmacher and Davis 2003; Lee 2005; Ayalew and Yamagishi 2005; Zhu and Huang 2006; Chen and Wang 2007; Akgün and Bulut 2007; Chauhan et al. 2010). It is useful when the outcome variable or dependent variable is binary or dichotomous. The dependent variable for this analysis is the absence or presence of a landslide.

Considering $\mathrm{n}$ independent variables $\mathrm{x}_{1}, \mathrm{x}_{2}, \mathrm{x}_{3}, \ldots \ldots, \mathrm{x}_{\mathrm{n}}$, affecting landslide occurrences, the vector $\mathrm{X}=\left(\mathrm{x}_{1}, \mathrm{x}_{2}, \mathrm{x}_{3}, \ldots \ldots\right.$ , $\mathrm{x}_{\mathrm{n}}$ ) has been defined. In logistic regression analysis, the logit $\mathrm{y}$ is assumed as a linear combination of independent variables and is given as follow.

$$
y=b_{0}+b_{1} x_{1}+b_{2} x_{2}+b_{3} x_{3}+\ldots \ldots+b
$$

Where, $\mathrm{b}_{0}$ is the constant of the equation, and $\mathrm{b}_{1}, \mathrm{~b}_{2}, \ldots, \mathrm{b}_{\mathrm{n}}$ are the coefficients of independent variables, $x_{1}, x_{2}, x_{3}, \ldots \ldots, x_{n}$. For landslide hazard assessment, the dependent variable is a binary variable, with values of 1 or 0 , representing the presence or absence of landslides. Quantitatively, the relationship between the occurrence and its dependency on several variables can be expressed as follow (Hosmer and Lemeshow 2000).

$$
P=1 / 1+e
$$

Where, $\mathrm{P}$ is the estimated conditional probability of landslide occurrence and e is the constant 2.718. From equation 9 and equation 10 , a relationship can be obtained in which the natural logarithm of the odds, $\log (\mathrm{P} / 1-\mathrm{P})$, is linearly related with the independent variables as follow.

$$
\log (P / 1-P)=b_{0}+b_{1} x_{1}+b_{2} x_{2}+b_{3} x_{3}+\ldots \ldots+b_{n} x_{n} \ldots .
$$

The goodness of fit of the model was tested with the Wald statistics and Hosmer-Lemeshow test (Hosmer and Lemeshow 2000). By examining the sign of a dependent variable's coefficient estimate, the effect of that variable on the probability of landslide occurrence can be determined. These values were utilized to decide final landslide hazard index (LHI) of the Jalad catchment of the study area.

\section{Data preparation}

The main steps for landslide hazard mapping are data collection and the construction of a spatial database, from which relevant causative factors were extracted. This is followed by assessment of the landslide hazard using the relationship between landslides and causative factors, and the subsequent validation of results. A key feature of this method is that the probability of landslide occurrence will be comparable with observed landslides.

For the modelling logistic regression, a number of thematic data of causative factors have been identified, including 1) slope, 2) slope aspect, 3) distance to drainage, 4) wetness index, 5) sediment transport index, 6) relief, 7) distance to transportation route, 8) curvature, 9) geology, 10) land cover, and 11) mean annual rainfall. Topographic maps and aerial photographs provided by the Department of Survey, Government of Nepal were considered as basic data sources for generating these layers. Field surveys were carried out for data collection and to prepare data layers of various factors. Landslide distribution maps of both catchments were also prepared in the field. These data sources were used to generate various thematic layers using the GIS software ILWIS 3.7. Brief descriptions of the preparation procedure of each data layer are provided here.

\section{Landslide characteristics and inventory maps}

A landslide inventory map shows the location of discernible failures. Two landslide inventory maps for Jalad and Charnath catchments were prepared. However, a detailed landslide map was prepared for the Jalad catchment and only recent locations of landslides were mapped in the Charnath catchment. Only scars (main failure portion) were used to delineate the landslides. With the use of field data and satellite image, 426 landslide scars were delineated in the Jalad catchment. Satellite image PRISM (Panchromatic Remote-sensing Instrument for Stereo Mapping) has $2.5 \mathrm{~m}$ resolution and very useful to recognise landslide image even from visual interpretation. The landslide scars mapped in field were again revised with PRISM data and final Landslide inventory maps were prepared for both catchments. All landslides were used to assess landslide hazard index from logistic regression modelling. Finally, to check the predictive power of model in all possible aspects of both models, the LHI of each class of causative factors estimated from the Jalad catchment was used for same class of causative factors in Charnath catchment. Moreover, prediction rates of the model were evaluated from landslide inventory of Charnath catchment. The inventory maps of both catchments are given in Fig. 14. 


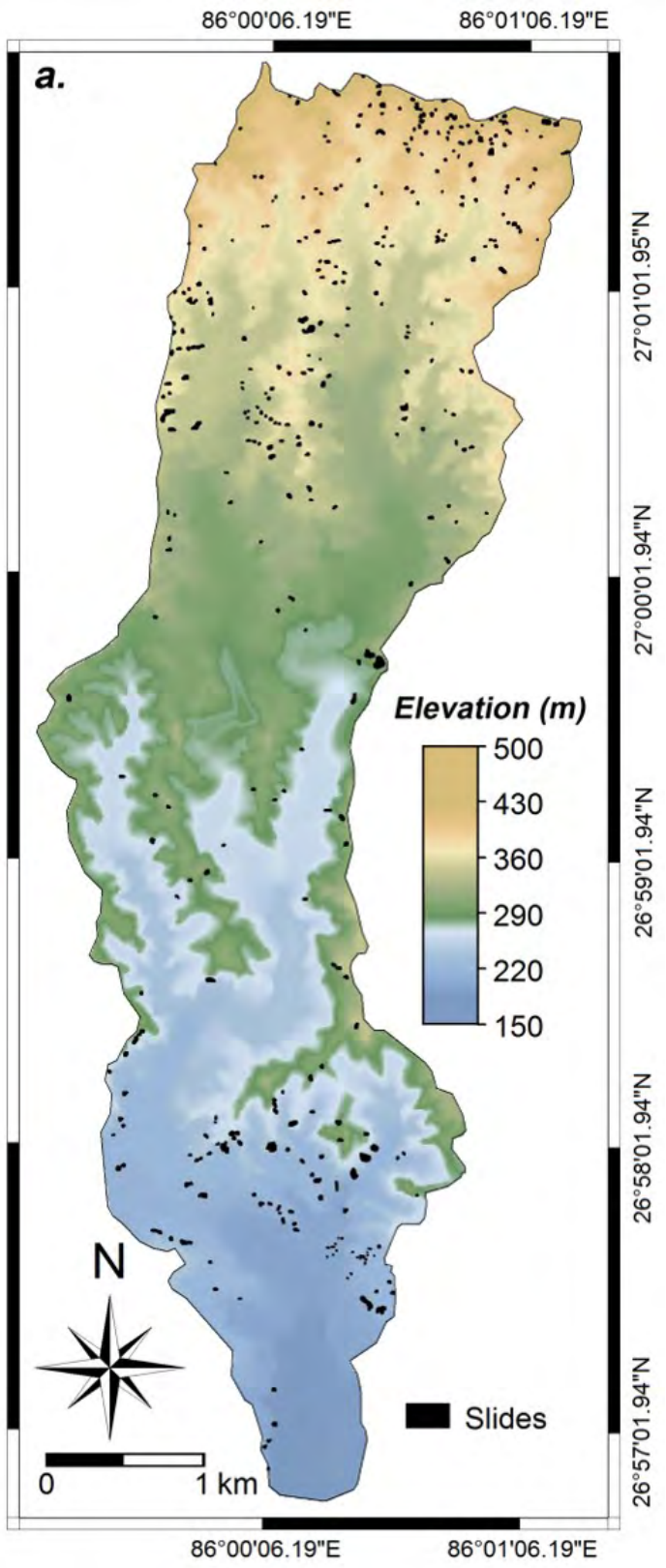

\section{Geological map}

Geology plays an important role in landslide susceptibility and hazard studies because different geological units have different susceptibilities to active geomorphological processes of the Himalaya. Sandstone, mudstone, siltstone and gravel conglomerate are main rocks of the selected catchments and they belong to the Lower and Upper Siwalik groups. For the geological map preparation, previous studies (DMG 2004; Ghimire et al. 2008) were consulted and boundaries of geological formations were checked in field visit and modified as per the field observations.

\section{Geomorphology related causative factors}

DEM was prepared with digital contour data $(1: 25,000$ scale) obtained from the Department of Survey, Government of Nepal. The DEM of study area was prepared in $10 \mathrm{~m} \times 10$ $\mathrm{m}$ pixel size. From this DEM, geomorphological thematic data

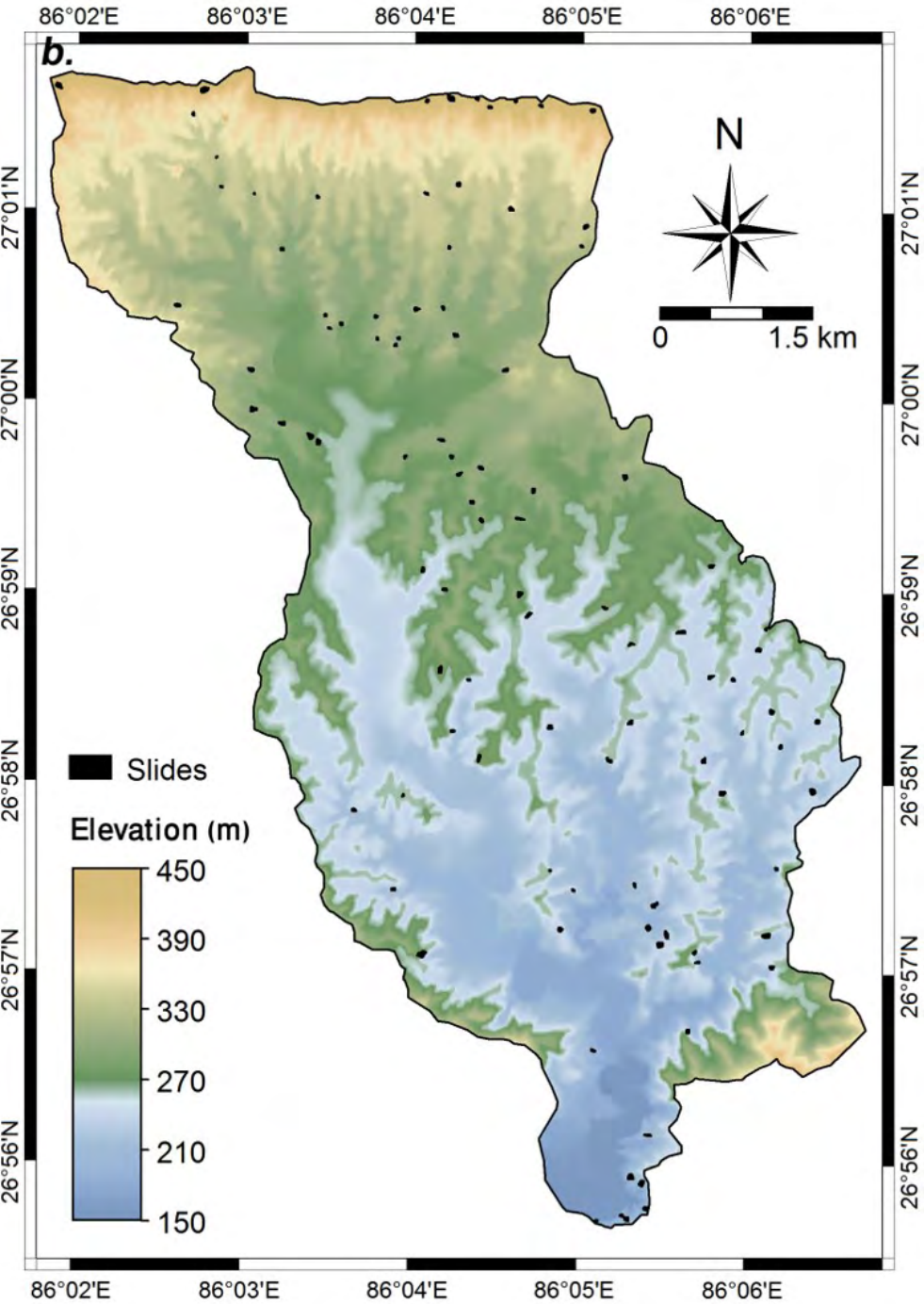

Fig. 14: Landslide inventory of a. Jalad catchment and b. Charnath catchment.

layers like slope, aspect, relative relief, distance to drainage, sediment transport index and wetness index were prepared.

\section{Slope and Aspect}

Slope classification was based on the slope angles of more than 70 landslides measured in the field. Field measurement signified that most of the landslides occur at slope angle between $15^{\circ}$ and $30^{\circ}$. Thus, total seven classes, $\angle 5^{\circ}, 5^{\circ}$ to $10^{\circ}$, $10^{\circ}$ to $15^{\circ}, 15^{\circ}$ to $20^{\circ}, 20^{\circ}$ to $25^{\circ}, 25^{\circ}$ to $30^{\circ},>30^{\circ}$ were used to prepare slope map. Aspect is referred to as the direction of maximum slope of the terrain surface. For the study area, it was divided into nine classes, namely, N, NE, E, SE, S, SW, $\mathrm{W}, \mathrm{NW}$ and Flat. Both slope and aspect maps were prepared in ILWIS 3.7 from DEM.

Relief

In this study, relative relief is computed as the difference between the maximum and minimum elevations within the given class of elevation. The relief was sliced into six classes at $50 \mathrm{~m}$ elevation difference. 


\section{Distance to drainage}

Location of the landslide from stream was considered as another geomorphology related causative factor. Subsequently, a distance to drainage map was generated as per the field identification that slope failure may be more frequent along stream, due to groundwater movement towards stream and toe undercutting. In order to produce the map showing distance to drainage, the drainage segment map was rasterised and the distance to the drainage was calculated in meters. The resultant map was then sliced into 6 classes. The six classes were $0 \mathrm{~m}$ to $20 \mathrm{~m}, 20 \mathrm{~m}$ to $40 \mathrm{~m}, 40 \mathrm{~m}$ to $60 \mathrm{~m}, 60 \mathrm{~m}$ to $80 \mathrm{~m}, 80 \mathrm{~m}$ to $100 \mathrm{~m},>100 \mathrm{~m}$.

\section{Curvature, Sediment transport index and Wetness index}

Following rainfall events, water flows from areas of convex curvature and accumulates in areas of concave curvature. This process is known as flow accumulation and is a measure of the land area that contributes surface water to an area where water can accumulate and those locations are likely to have a high slope failure incidence.

Other three slope morphology related parameters namely: sediment transport index, wetness index and curvature were considered for slope morphology related parameter study. Sediment transporting process is enhancing slope failure mechanism extensively in Siwalik. Sediment transport index accounts for the effect of topography on erosion. The planimetric catchment area is used to calculate this index. The wetness index sets catchment area in relation to the slope gradient. An idea of the spatial distribution of zones of saturation can be obtained from wetness index (Moore et al. 1991).

\section{Distance to transport route}

In the study area, road access was prime factor of forest degradation. As a result, many landslides are prominent in the degraded forest area. Every day, wood smuggling is increasing and along the transport route, forest is also declining. Thus, distance to road map was generated as per the hypothesis that landslides may be more frequent along roads and trails, owing to excessive forest declination along the roads and trails.

\section{Land cover map}

More than $90 \%$ the study area is covered by forest. To interpret land cover of the area, Normalized Difference Vegetation Index (NDVI) was considered and the NDVI map was obtained from Landsat TM satellite image acquired on 1 November 2005. The NDVI value was calculated using the $\mathrm{NDVI}=(\mathrm{IR}-\mathrm{R}) /(\mathrm{IR}+\mathrm{R})$ formula, where IR is near-infrared band image and $\mathrm{R}$ is red band image of Landsat TM. The NDVI value denotes areas of vegetation in an image. The presence of dense green vegetation implies high NDVI values, due to high concentration of chlorophyll resulting in a low reflectance in the red band as well as due to the high stacking of leaves. Sparse vegetation, on the other hand, implies low NDVI values. Likewise, water, and clouds have larger visible reflectance than near-infrared reflectance. Thus, these features yield negative index values. Rock and bare soil areas have similar reflectance in the two bands and result in vegetation indices near zero. To prepare categorical thematic layers of NDVI for Jalad and Charnath catchments, the cumulative frequency curve of NDVI values has been segmented into five classes representing equal distribution to yield five NDVI classes $0 \%-20 \%, 20 \%-40 \%$, $40 \%-60 \%, 60 \%-80 \%$, and $80 \%-100 \%$

\section{Rainfall map}

Rainfall is an extrinsic variable in hazard analysis, and the spatial distribution of mean annual rainfall is commonly used in this statistical hazard analysis (Dahal 2008a; Regmi et al. 2010). Rainfall stations around the study area were used to prepare mean annual rainfall map. The spatial distribution of rainfall was calculated through the application of the inverse distance squared method in ILWIS 3.7. The resulting map was sliced to give a raster map with four classes having a $<1,500$ $\mathrm{mm}, 1,500 \mathrm{~mm}-1,550 \mathrm{~mm}, 1,500 \mathrm{~mm}-1,600 \mathrm{~mm}$, and $>1,600$ $\mathrm{mm}$ for the Jalad catchment and $<1,450 \mathrm{~mm}, 1,450 \mathrm{~mm}-1,500$ $\mathrm{mm}, 1,500 \mathrm{~mm}-1,550 \mathrm{~mm}$, and $>1,550 \mathrm{~mm}$ for Charnath catchment. All the data layers such as slope, slope aspect, distance to drainage, wetness index, sediment transport index, relief, distance to transportation route, curvature, geology, NDVI, and mean annual rainfall of both catchments are given in Fig. 15 and Fig. 16.

\section{Analysis and results}

In this study, data from all over the study area (Guzzetti et al. 1999) was used for logistic regression modelling. In this study the causative parameters were categorised into various classes and each parameter was nominal variable. So these variables were converted to a nominal to a numeric by coding. For this purpose, the landslide density (Carrara 1983) was used to transform nominal variable to numeric variable.

The landslide density is used to transform nominal variable to numeric variable. It avoids the creation of an excessively high number of dummy variables. Following formula was used to calculate the densities of landslide in each class of causative factors.

$$
L D=\frac{l_{i} / c_{i}}{\sum_{i=1}^{n} l_{i} / c_{i}}
$$

Where, LD is landslide density, ci is the area of ith class of a factor (such as slope class $10^{\circ}$ to $15^{\circ}$ ), li is landslide area within ith class of a factor ( such as slope $10^{\circ}$ to $15^{\circ}$ ), $n$ is the total number of a certain factor. Then the parameter maps were overlaid with the landslide inventory map to calculate landslide densities based on equation (12). All the classes of causative factors were converted to numerical variable landslide density as shown in Table 2. The domain of landslide inventory map was changed from landslide present and landslide absent to numerical variables 1 (for landslide present) and 0 (for landslide absent). All spatial databases of causative parameters and landslide inventory were exported to statistical package (SPSS) and logistic regression analysis was performed for the Jalad catchment. In addition, logistic regression formulae were created. 

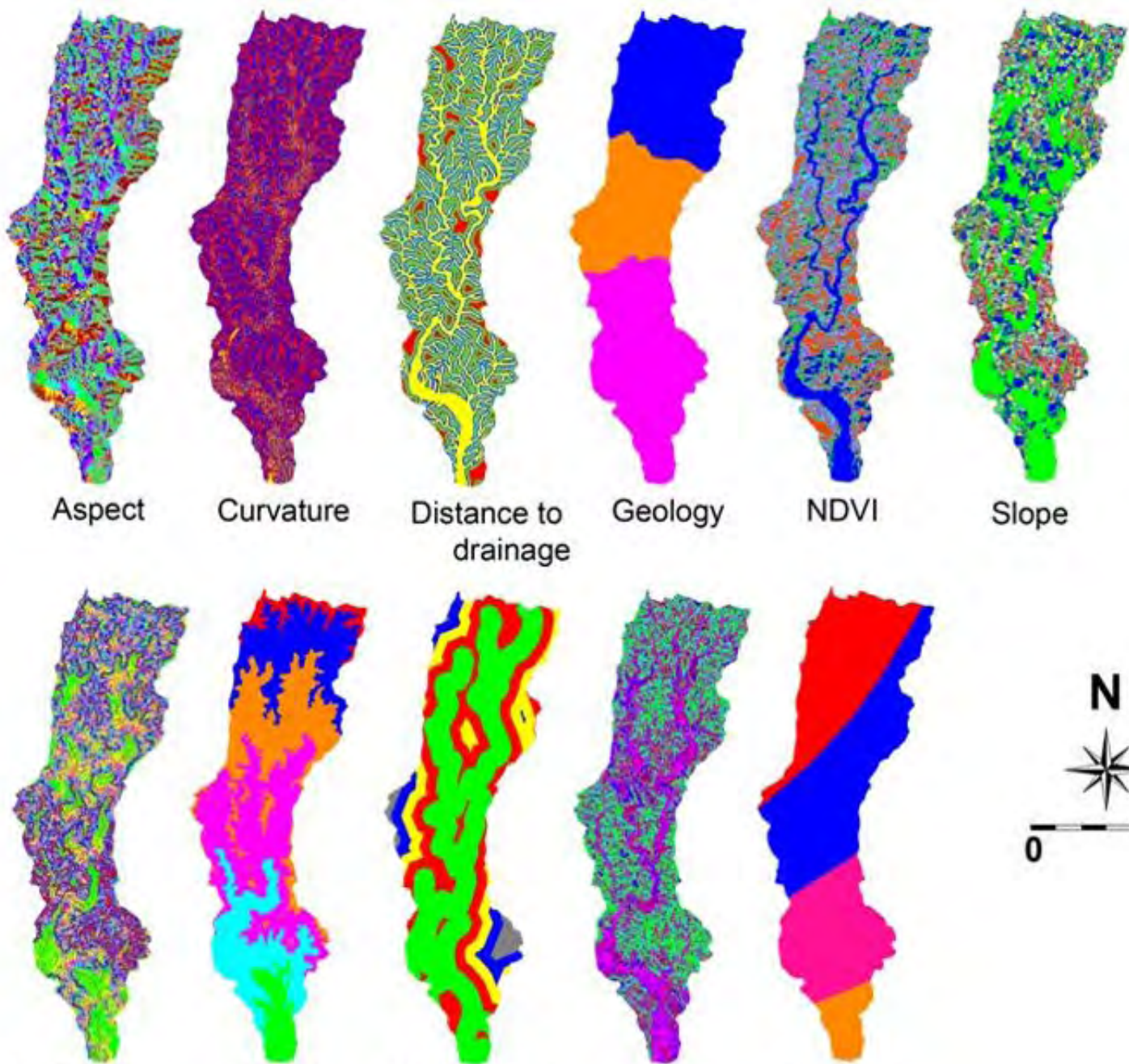

Slope

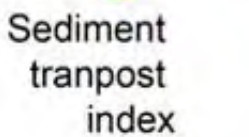

Relief

Distance to transportation routes

\section{LEGEND}

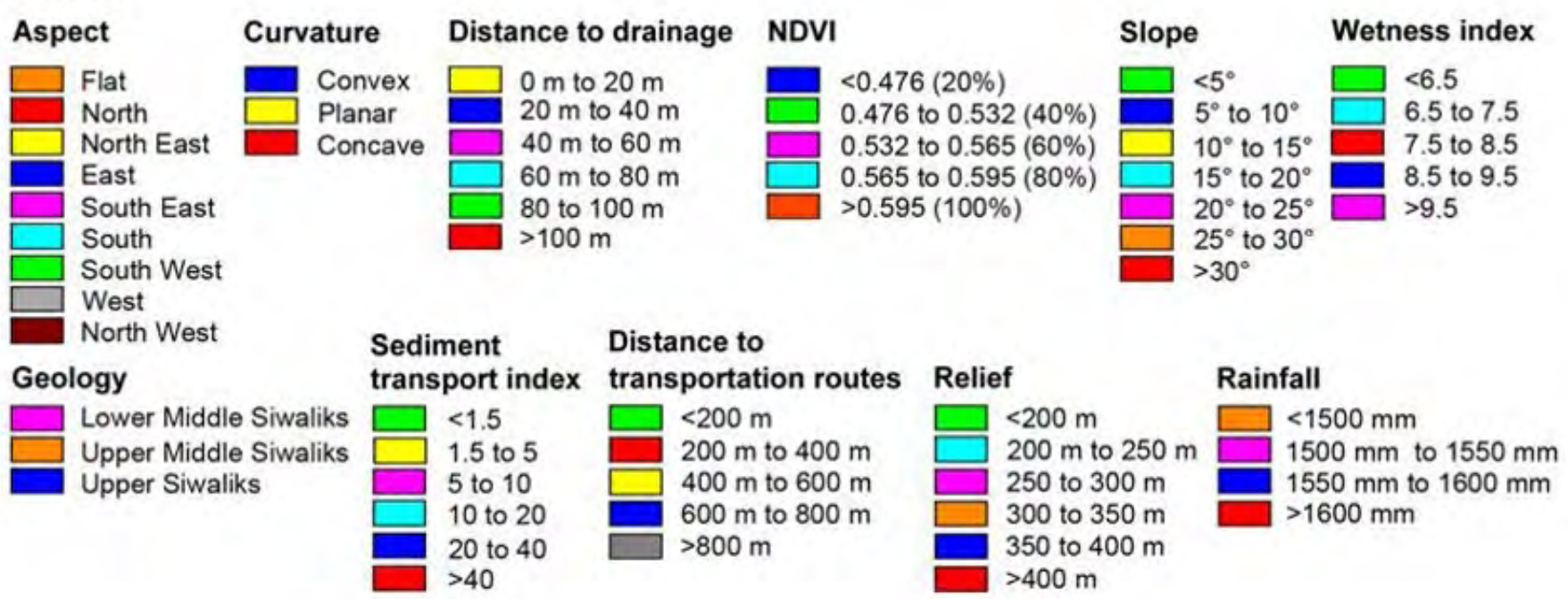

Fig. 15: Various data layers of Jalad catchment prepared for multivariate analysis. 


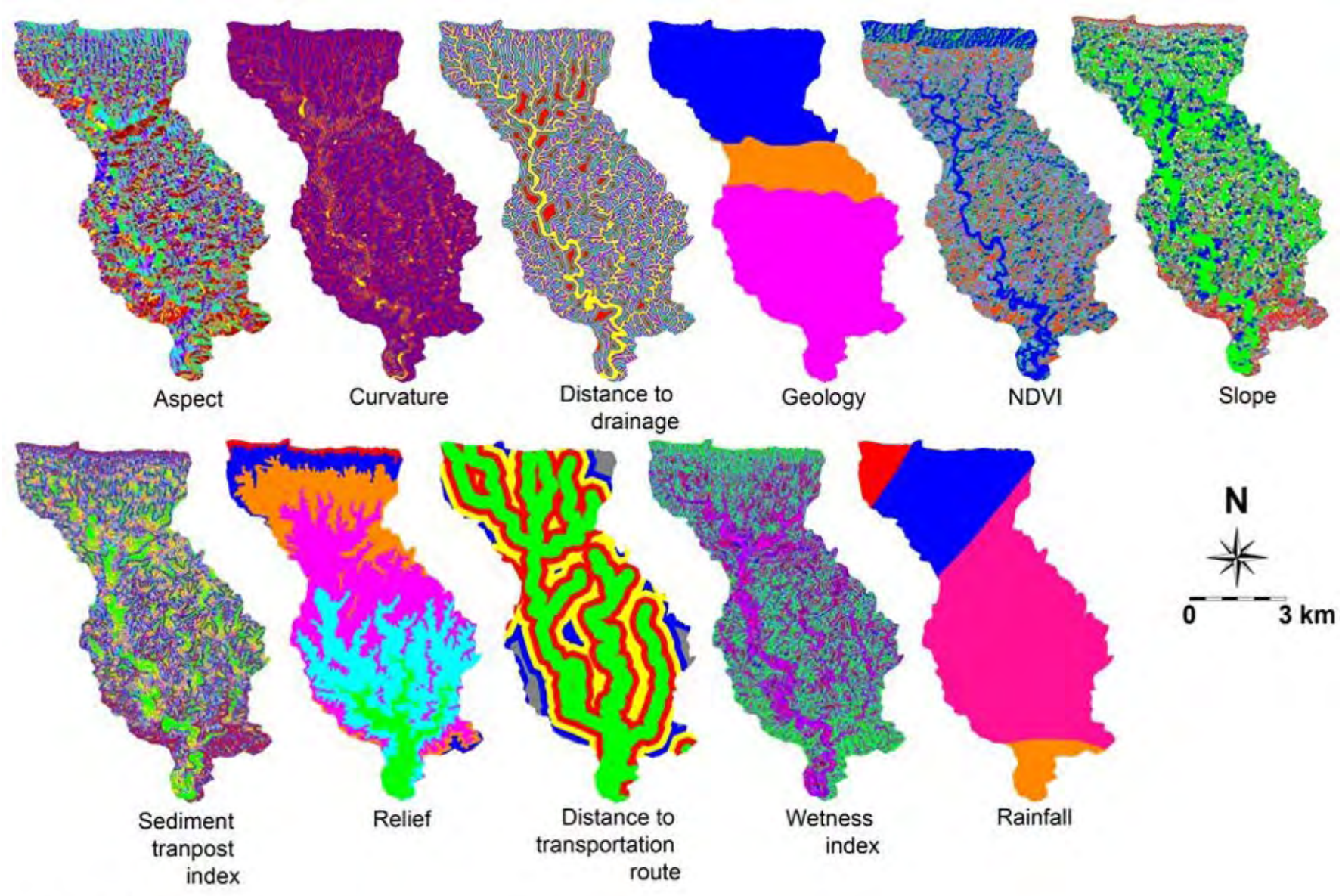

\section{LEGEND}

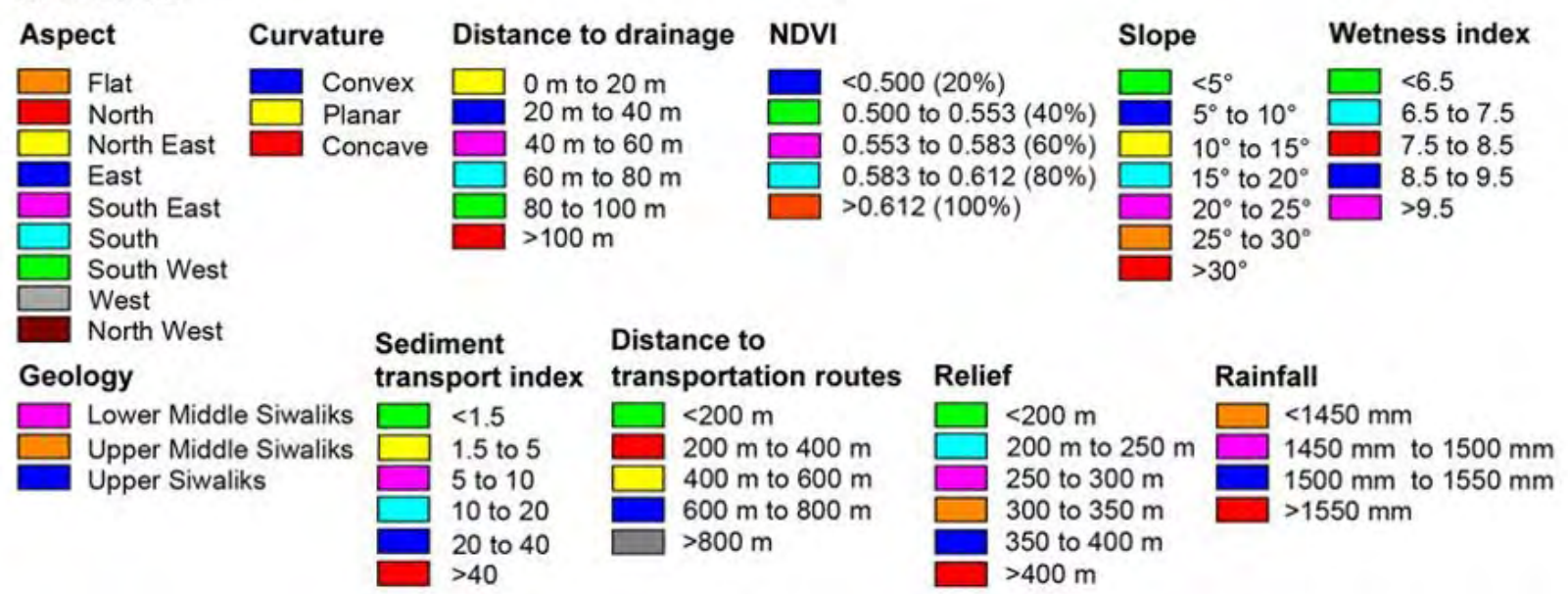

Fig. 16: Various data layers of Charnath catchment prepared for multivariate analysis.

All data are used in the logistic regression modelling and the overall model statistics of the regression conducted in this study is given in Table 3. Hosmer-Lemeshow test showed that the goodness of fit of the equation can be accepted because the significance of chi-square is 0.122 . In Hosmer-Lemeshow test, if significance of chi-square value is less than 0.05 , the logistic regression model could not be accepted (Zhu and Huang 2006; Chen and Wang 2007). The value of Cox and Snell R2 and Nagelkerke R2 showed that the independent variables can explain the dependent variable in an acceptable way. Similarly,
ROC (Receiver Operating Characteristics) value of the model is 0.795 . For the valid regression model, ROC value should be greater than 0.5 (Hosmer and Lemeshow 2000). Significance of the Wald statistic for all causative factors is less than 0.05 and it confirms that independent variables have significantly predicted the outcome. From the logistic regression modelling of Jalad catchment, following logistic regression equations was obtained.

$$
\begin{array}{r}
\log (\mathrm{P} / 1-\mathrm{P})=-11.860+(4.736 \times \text { Slope })+(8.059 \times \text { Aspect }) \\
+(0.696 \times \text { Curvature })+(2.499 \times \text { Relief })+(8.485 \times \text { Distance }
\end{array}
$$


to Drainage $)+(7.630 \times \mathrm{NDVI})+(3.656 \times$ Transportation Route $)-(0.39 \times$ Geology $)+(2.107 \times$ Wetness Index $)-$ $(2.696 \times$ Sediment Transport Index $)+(2.576 \times$ Rainfa 11)..

The factors given in the equation (13) represent the landslide density values. For application of model in the Charnath catchment, value of landslide density of each class of all causative factors calculated from the Jalad catchment were replicated in the Charnath catchment and equation (10) was applied to estimate hazard probability of the Charnath catchment after logistic regression modelling. Here also, special consideration was made for NDVI and rainfall parameters. For NDVI, equal distribution class $(0 \%-20 \%, 20 \%-40 \%, 40 \%$ $60 \%, 60 \%-80 \%$, and $80 \%-100 \%$ ) of Jalad catchment were considered as same class of NDVI parameter in Charnath catchment. For the rainfall, landslide density of $<1,500 \mathrm{~mm}$, $1,500 \mathrm{~mm}-1,550 \mathrm{~mm}, 1,500 \mathrm{~mm}-1,600 \mathrm{~mm}$, and $>1600 \mathrm{~mm}$ estimated from the Jalad catchment were replicated for classes $<1,450 \mathrm{~mm}, 1,450 \mathrm{~mm}-1,500 \mathrm{~mm}, 1,500 \mathrm{~mm}-1,550 \mathrm{~mm}$, and $>1,550 \mathrm{~mm}$ of Charnath catchment. Here also, this assumption was made as per the fact that consequences of higher range of rainfall for landsliding are same in both catchments. Moreover, slight difference of rainfall value range $(50 \mathrm{~mm})$ in the rainfall classes certainly will not introduce a huge uncertainty in the result.

\section{VALIDATION}

The landslide hazard index maps of Charnath catchment after logistic regression modelling was prepared without any consideration of previous landslides occurrences in Charnath catchment. To understand its accuracy and to validate logistic regression modelling, the map was used to estimate prediction rate. In the science of landslide hazard and susceptibility analysis, success rate and prediction rate are used to validate hazard or susceptibility indexes (Chung and Fabbri 1999; van Westen et al. 2003; Lee et al. 2007, Lee 2004, Dahal 2008a, Dahal 2008b, Regmi et al. 2010, von Ruette et al. 2011). The success rate indicates what percentage of all landslides occurs in the classes with the highest value of hazard. As mentioned in earlier section, when old landslides are used for LHI calculation and new landslides are used for prediction, the calculated accuracy rate is called prediction rate. In this study, instead of using new landslides of same area (Jalad catchment), landslides from a different area (Charnath catchment) was selected for estimation of prediction rate.

A ROC (Receiver Operating Characteristics) curve approach is used to analyze the prediction accuracy of the proposed models. The ROC value is measure of success rate and prediction rate usually obtained from ROC curve. These ROC curves give area under the curve and it is a measure of goodness of fit. The ROC curves of Jalad catchment account the success rate of the models (Fig. 17a), whereas ROC curves of the Charnath catchment (Fig. 17b) depict prediction rate of the models. From the ROC curve, the success rate and prediction rate of logistic regression model were 0.795 and 0.749 , respectively.

\section{Landslide hazard zonation maps}

From the independent evaluation of accuracy of the logistic regression models in the Siwalik for landslide hazard assessment, it was found that logistic regression model had acceptable accuracy. Considering the prediction rate of logistic regression from ROC curve, five landslide hazard classes were defined: very low ( $<30 \%$ class of low to high LHI value), low (30\% - 50\% class of low to high LHI value), moderate $(50 \%$ $70 \%$ class of low to high LHI value), high $(70 \%-90 \%$ class of low to high LHI value), and very high ( $>90 \%$ class of low to high LHI value, i.e., most higher LHI values). Then, landslide hazard zonation maps after logistic regression modelling of both catchments were prepared (Fig. 18).
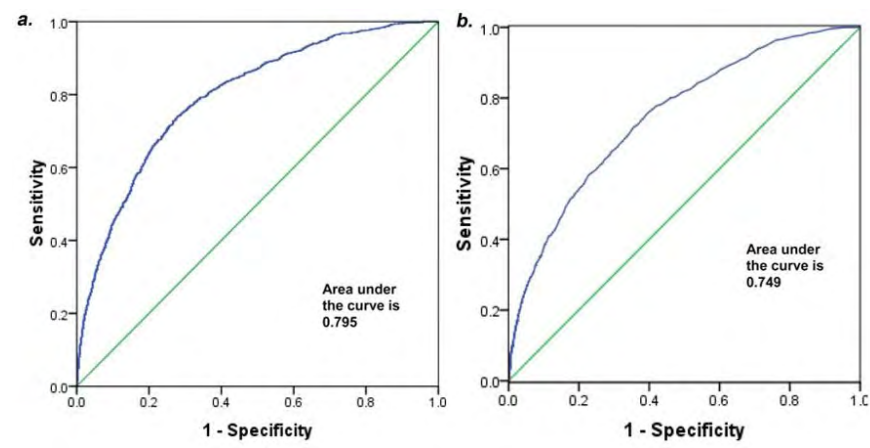

Fig. 17: Success rate and prediction rate of the model. a. is success rate of the modelling resulted from Jalad catchment and $b$. is prediction rate of modelling after replication of LSI value in Charnath watershed.

\section{CONCLUSION}

In this paper, a brief discussion about landslides hazard and susceptibility analysis methods are performed. Although, various methodologies have been proposed for landslide susceptibility and hazard mapping; in this paper, three statistical methods, namely weights-of-evidence modeling, information value modeling and logistic regression modeling are described with three case studies. Landslides hazard and susceptibility replication procedures are also described with an illustration. In many approach of modelling in GIS, model is always employed in only one area. The approaches used in that model, when employ in other area, there is very few chance of success to get best result. This usually happen because there is lack of similarity of intrinsic variables in the selected sites. But, in this paper, landslide hazard mapping in two catchments of different area shows landslide hazard index can be replicated also. Likewise, the approaches of GIS-based statistical modelling of landslide hazard and susceptibility can give good results even in catchment scale mapping, if the analysis is performed in field oriented data.

Statistical modelling based on weights-of-evidence modelling and information value methods are also described with an example from the Lesser Himalayan region of Nepal. The landslide hazard value estimated from different time-based landslide data and eleven factor maps reveals more or less a similar degree of accuracy ranging from $80 \%$ to $86 \%$. In many 

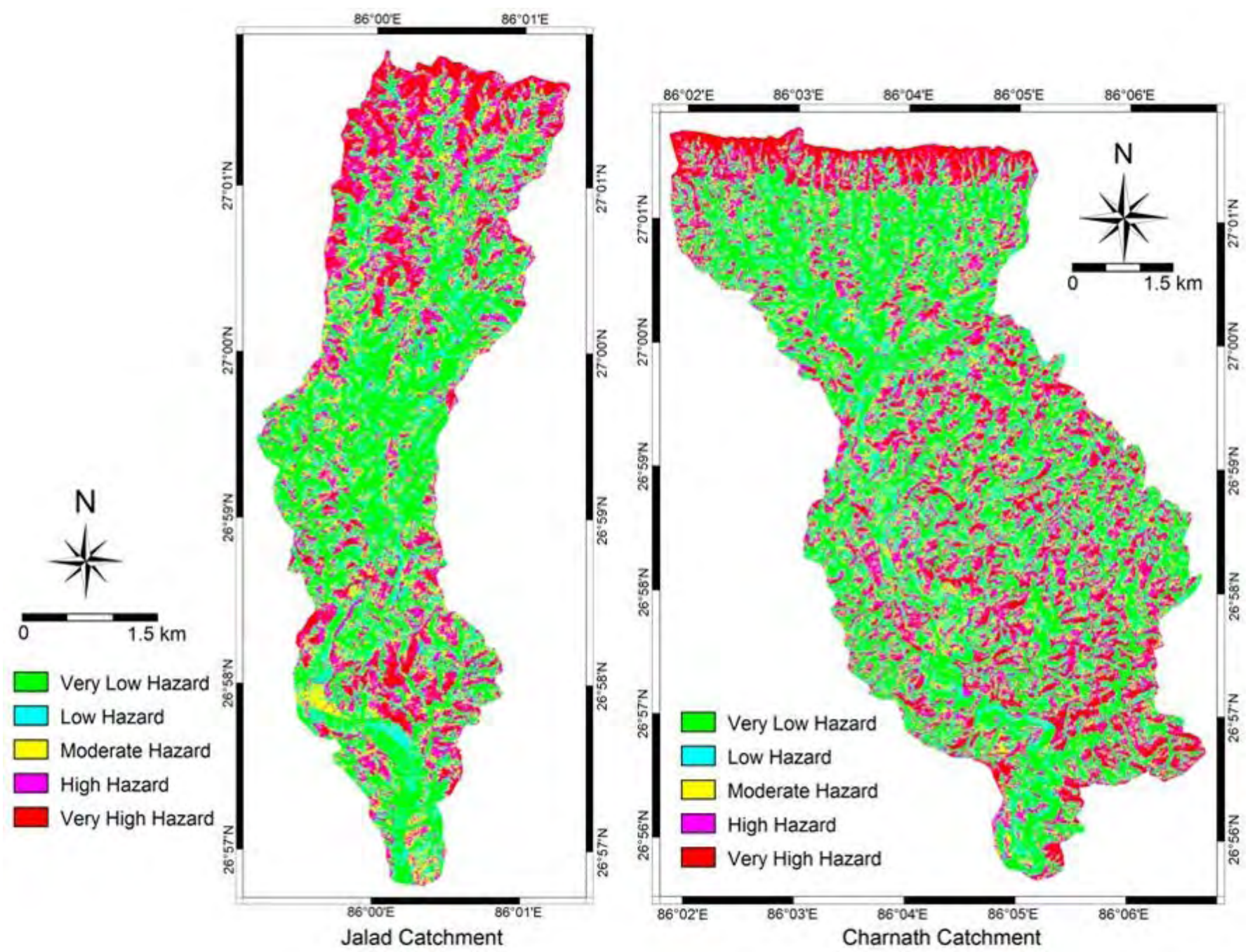

Fig. 18: Landslide Hazard maps of Jalad catchment and Chartnath catchment after the logistic regression modeling.

approaches to weights-of-evidence modelling of landslide hazard or susceptibility assessment in GIS, the model validation process is always dependent on the trained landslide data and the same landslide data are used for verification. In contrast, in this work the model was also verified independently with timebased new landslide data and results are very promising, with independent prediction rates of $80 \%$ accuracy. This validates bivariate statistical modelling for landslide hazard assessment for the Lesser Himalayan region.

JTC-1 has suggested that a landslide hazard map should consider landslide magnitude probability or distribution probability or temporal variation probability (Fell et al. 2008), However, in this paper, an event based landslides are considered as proxy parameter for temporal variation probability and landslide hazard zonation map was prepared with field and DEM based data.

The vigorous evaluation of predictive factors used in statistical modeling suggests that the role of geomorphology and human intervention-related factors is very significant for landslide processes. The probability values estimated in this kind of predictive modelling are not absolute and represent a relative degree of hazard or susceptibility. However, they can provide an appropriate and valid measure of landslide initiation locality on slopes. Likewise, the methodology seems to have extensive applicability in the mountainous terrain of the Himalaya, with the limitation that knowledge of past landslide information affects the final probability values calculated by the model.

\section{REFERENCES}

Acharya, K. K., 2001, Geology and structure of the Pharping Raniban area central Nepal, M. Sc. Thesis, Central Department of Geology, Tribhuvan Univ. (Unpublished), 58 p.

Agterberg, F. P., 1992, Combining indicator patterns in weights of evidence modeling for resource evaluation. Natural Resources Research, v. 1(1), pp. 39-50.

Agterberg, F. P., Bonham-Carter, G. F., Cheng, Q., and Wright, D. F., 1993, Weights of evidence modeling and weighted logistic regression for mineral potential mapping, In: Davis, J. C., and Herzfeld, U. C. (Eds.) Computers in Geology, 25 Years of Progress. Oxford Univ. Press, Oxford, pp. 13-32.

Akgün, A., and Bulut, F., 2007, GIS-based landslide susceptibility for Arsin-Yomra (Trabzon, North Turkey) region. Environ. Geol., v. 51 , pp. $1377-1387$ 
Aleotti, P., and Chowdhury, R., 1999, Landslide hazard assessment: summary review and new perspectives. Bull. Eng. Geol. Environ., v. 58, pp. 21-44.

Atkinson, P. M., and Massari, R., 1998, Generalized linear modelling of landslide susceptibility in the Central Apennines, Italy. Computer Geoscience, v. 24, pp. 373-385.

Ayalew, L., and Yamagishi, H., 2005, The application of GIS-based logistic regression for landslide susceptibility mapping in the Kakuda-Yahiko Mountains, Central Japan. Geomorphology, v. 65, pp. 15-31.

Ayalew, L., Yamagishi, H., and Ugawa, N., 2004, Landslide susceptibility mapping using GIS based weighted linear combination, the case in Tsugawa area of Agano River, Niigata Prefecture, Japan. Landslides, v. 1, pp. 73-81.

Baum, R. L., Savage, W. Z., and Godt, J. W., 2002, TRIGRS- A Fortran Program for Transient Rainfall Infiltration and GridBased Regional Slope-Stability Analy sis, USGS Open-file report 02-424.

Bonham-Carter, G. F., 2002, Geographic information systems for geoscientist: Modelling with GIS. In: Merriam, D. F. (Ed.), Computer Methods in the Geosciences, v. 13, pp. 302-334.

Bonham-Carter, G. F., Agterberg, F. P., and Wright, D. F., 1988, Integration of geological datasets for gold exploration in Nova Scotia. Photogram. Eng. Remo. Sens., 54, pp. 1585-1592.

Bonham-Carter, G. F., Agterberg, F. P., and Wright, D. F., 1989, Weights of evidence modelling: a new approach to mapping mineral potential. Statistical Applications in the Earth Science, Geological Survey of Canada Paper 89-9, pp. 171-183.

Burbank, D. W., Beck, R. A., and Mulder, T., 1996, The Himalayan foreland basin, in The Tectonic Evolution of Asia, edited by Yin, A. and Harrison, M., Cambridge Univ. Press, pp. 149-188.

Carrara, A., 1983, Uncertainty in Evaluating Landslide Hazard and Risk. In: Nemec, J., Nigs, J. M., Siccardi, F. (Eds.), Prediction and Perception of Natural Hazards. Kluwer, Dordrecht, The Netherlands, pp. 101-111.

Carrara, A., Cardinali M., Detti R., Guzzetti, F., Pasqui, V., and Reichenbach, P., 1991, GIS techniques and statistical models in evaluating landslide hazard. Earth Surface Processes and Landforms, v. 16, pp. 427-445.

Cascini, L., 2008, Applicability of landslide susceptibility and hazard zoning at different scales Eng. Geol., v. 102, pp. 164-177.

Çevik, E., Topal, T., 2003, GIS-based landslide susceptibility mapping for a problematic segment of the natural gas pipeline, Hendek (Turkey). Environ. Geol., 44, pp. 949-962.

Chauhan, S., Sharma, M., and Arora, M. K., 2010, Landslide susceptibility zonation of the Chamoli region, Garhwal Himalayas, using logistic regression model. Landslides, v. 7, pp. 411-423.

Chen, Z., and Wang J., 2007, Landslide hazard mapping using logistic regression model in Mackenzie Valley Canada. Nat. Hazards, v. 42, pp. 75-89.

Chung, C.-J. F., and Fabbri, A. G., 1999, Probabilistic prediction models for landslide hazard mapping. Photogrammetric Engineering and Remote Sensing, v. 65, pp.1389-1399.

Crozier, M. J., 1999, Prediction of rainfall-triggered landslides: a test of the antecedent water status model. Earth Surface Processes and Landforms, v. 24, pp. 825-833.

Crozier, M. J., and Glade T., 2005, Landslide hazard and risk: Issues, Concepts and Approach. In: Glade, T., Anderson, M. \& M. Crozier (Eds.): Landslide hazard and risk.- Wiley, Chichester, pp.1-40.

Dahal, R. K., Hasegawa, S., Bhandary, N. P., Poudel, P. P., Nonomura A., and Yatabe, R., 2012, A replication of landslide hazard mapping at catchment scale. Geomatics, Natural Hazards and Risk, v. 3(2), pp. 161-192.

Dahal, R. K., Hasegawa, S., Nonomura, A., Yamanaka, M., Dhakal, S., and Paudyal, P., 2008a, Predictive modelling of rainfallinduced landslide hazard in the Lesser Himalaya of Nepal based on weights-of-evidence. Geomorphology, v. 102(3-4), pp. 496-510.

Dahal, R. K., Hasegawa, S., Nonomura, A., Yamanaka, M., Masuda, T., and Nishino, K., 2008b, GIS-based weights-of-evidence modelling of rainfall-induced landslides in small catchments for landslide susceptibility mapping. Environ. Geol. v. 54(2), pp. 314-324

Dahal, R. K., Hasegawa, S., Nonomura, A., Yamanaka, M., and Dhakal, S., 2008c, DEM-based deterministic landslide hazard analysis in the Lesser Himalaya of Nepal, Georisk: Assessment and Management of Risk for Engineered Systems and Geohazards, v. 2(3), pp. 161-178.

Dai, F. C., and Lee, C. F., 2002, Landslide characteristics and slope instability modeling using GIS, Lantau Island, Hong Kong. Geomorphology, v. 42(3-4), pp. 213-228.

Dai, F. C., Lee, C. F., Li, J., and Xu, Z. W., 2001, Assessment of landslide susceptibility on the natural terrain of Lantau Island, Hong Kong. Environ. Geol., v. 40, pp. 381-391.

Dai, F. C., and Lee, C. F., 2001, Terrain-based mapping of landslide susceptibility using a geographical information system: a case study. Canadian Geotech. Jour., v. 38, 911-923.

Dai, F. C., and Lee, C. F., 2003, A spatiotemporal probabilistic modeling of storm-induced shallow landsliding using aerial photographs and logistic regression. Earth Surface Processes and Landforms, v. 28, 527-545.

Dai, F. C., Lee, C. F., Tham, L. G., Ng, K. C., and Shun, W. L., 2004, Logistic regression modelling of storm-induced shallow landsliding in time and space on natural terrain of Lantau Island, Hong Kong. Bull. Eng. Geol. Environ., v. 63, pp. 315-327.

Dhakal, A. S., and Sidle, R. C., 2004, Distributed simulations of landslides for different rainfall conditions. Hydrological Processes, v. 18, pp. 757-776.

Dietrich, W. E., Reiss, R., Hsu, M., and Montgomery, D. R., 1995, A process-based model for colluvial soil depth and shallow landsliding using digital elevation data. Hydrological Processes, v. 9, pp. 383-400.

DMG, 2004, Geological Map of Petroleum Exploration Block-8, Janakpur, Central Nepal, Department of Mines and Geology, Kathmandu, Nepal.

Ermini, L., Catani, F., and Casagli, N., 2005, Artificial Neural Networks applied to landslide susceptibility assessment. Geomorphology, v. 66, pp. 327-343.

Fall, M., Azam, R., and Noubactep, C., 2006, A multi-method approach to study the stability of natural slopes and landslide susceptibility mapping. Eng. Geol., v. 82 (4), pp. 241-263.

Fell, R., Corominas, J., Bonard, C., Cascini, L., Leroi, E., and Savage, W. Z., 2008, Commentary guidelines for landslide susceptibility, hazardand risk zoning for land use planning. Eng. Geol., v. 102(3-4), pp. 85-98.

Frattini, P., Crosta, G., and Carrara, A., 2010, Techniques for evaluating the performance of landslide susceptibility models. Eng. Geol., v. 111, pp. 62-72.

Ghimire, M., Paudyal, P., Pathak, M., Baskota, T. R., and Bogati, R., 2008, Impact of hydro-geological processes and land degradation on livelihood strategy in the Churia and Terai region of Nepal, Care Nepal, pp. 1-130.

Glade, T., Crozier, M., and Smith, P., 2000, Applying probability determination to refine landslide-triggering rainfall thresholds 
using an empirical Antecedent Daily Rainfall Model. Pure and Applied Geophysics, v. 157, pp. 1059-1079.

Gökceoglu, C., and Aksoy, H., 1996, Landslide susceptibility mapping of the slopes in the residual soils of the Mengen region (Turkey) by deterministic stability analyses and image processing techniques. Eng. Geol., v. 44, pp. 147-161.

Guzzetti, F., 2005, Landslide Risk Assessment, PhD Thesis. Mathematik und Naturwissenschaftlichen Fakultät Der Rheinischen Friedrich Wilhelms Univestität Bonn (Unpublished), $389 \mathrm{p}$.

Guzzetti, F., Carrara, A., Cardinali, M., and Reichenbach, P., 1999, Landslide hazard evaluation: a review of current techniques and their application in a multi-scale study. Geomorphology, v. 31, pp. 181-216.

Guzzetti, F., Reichenbach, P., Ardizzone, F., Cardinali, M., and Galli, M., 2006, Estimating the quality of landslide susceptibility models. Geomorphology, v. 81, 166-184.

Hammond, C., Hall, D., Miller, S., and Swetik, P., 1992, Level I Stability analysis (LISA), Documentation for Version 2.0, Gen. Tech. Rep. INT-285, Ogden, UT: U.S. Department of Agriculture, Forest Service, Intermountain Research Station, $190 \mathrm{p}$.

Hosmer, D. W., and Lemeshow, S., 2000, Applied logistic regression. John Wiley \& Sons, Inc., 375 p.

Iverson, R. M., 2000, Landslide triggering by rain infiltration, Water Resources Research, v. 36(7), pp. 1897-1910.

Jade, S., and Sarkar S., 1993, Statistical models for slope instability classification. Eng. Geol., v. 36, pp. 91-98.

Kanungo, D. P., Arora, M. K., Sarkar, S., and Gupta, R. P., 2006, A comparative study of conventional, ANN black box, fuzzy and combined neural and fuzzy weighting procedures for landslide susceptibility zonation in Darjeeling Himalayas. Eng. Geol., v. $85,347-366$.

Komac, M., 2005, A landslide susceptibility model using the analytical hierarchy process method and multivariate statistics in perialpine Slovenia. Geomorphology, v. 74, pp. 17-28.

Lan, H. X., Zhou, C. H., Wang, L. J., Zhang, H. Y., and Li, R. H., 2004, Landslide hazard spatial analysis and prediction using GIS in the Xiaojiang watershed, Yunnan, China. Eng. Geol., v. 76, pp. 109-128.

Lee, S., 2004, Application of likelihood ratio and logistic regression models to landslide susceptibility mapping in GIS. Environmental Management, v. 34, pp. 223-232.

Lee, S., 2005, Application of logistic regression model and its validation for landslide susceptibility mapping using GIS and remote sensing data. Int. Jour. Remote Sens., v. 26, pp.14771491.

Lee, S. and Choi, J., 2004, Landslide susceptibility mapping using GIS and the weights-of-evidence model. Int. Jour. Geog. Info. Sci., v. 18 , pp. $789-814$

Lee, S., Choi, J., and Min, K., 2002, Landslide susceptibility analysis and verification using the Bayesian probability model. Environ. Geol., v. 43, pp. 120-131

Lee, S., Ryu, J., and Kim, I., 2007, Landslide susceptibility analysis and its verification using likelihood ratio, logistic regression and artificial neural network models: case study of Youngin, Korea. Landslides, v. 4, pp. 327-338

Lee, S., and Sambath, T., 2006, Landslide susceptibility mapping in the Damrei Romel area, Cambodia using frequency ratio and logistic regression models. Environ. Geol., v. 50, pp. 847-855

Lee, S., and Min, K., 2001, Statistical analysis of landslide susceptibility at Yongin, Korea. Environ. Geol., v. 40, pp. 1095-1113.
Lee, S., Ryu, J. H., Won, J. S., and Park, H. J., 2004, Determination and application of the weights for landslide susceptibility mapping using an artificial neural network. Eng. Geol., v. 71, pp. 289-302.

Montgomery, D. R., and Dietrich, W. E., 1994, A physical based model for the topographic control on shallow landsliding, Water Resources Research, v. 30(4), pp. 1153-1171.

Moore, I. D., Grayson, R. B., and Ladson, A. R., 1991, Digital terrain modeling - a review of hydrological, geomorphological, and biological applications. Hydrol. Process, v. 5, pp. 3-30

Neuhäuser, B., and Terhorst, G., 2007, Landslide susceptibility assessment using "weights-of-evidence" applied to a study area at the Jurassic escarpment (SW-Germany). Geomorphology, v. 86, pp. 12-24.

Ohlmacher, G. C., and Davis, J. C., 2003, Using multiple logistic regression and GIS technology to predict landslide hazard in northeast Kansas, USA. Eng. Geol., v. 69(3-4), 331-343.

Pack, R. T., Tarboton, D. G., and Goodwin, C. N., 1998, SINMAP, A stability index approach to terrain stability hazard mapping, User's Manual (available at http://www.tclbc.com), Utah State University, Terratech Consulting Ltd., Canadian Forest Products Ltd, C.N. Goodwin Fluvial System Consulting, 68 p.

Pack, R. T., Tarboton, D. G., and Goodwin, C. N., 2001, SINMAP approach to terrain stability mapping. In: Moore, D. P. and Hungr, O. (Eds.), proceedings of International Conference of International Association for Engineering Geology and the Environment, AA Balkema, Rotterdam, Netherlands, pp.11571165 .

Pradhan, B., and Lee, S., 2010, Landslide susceptibility assessment and factor effect analysis: backpropagation artificial neural networks and their comparison with frequency ratio and bivariate logistic regression modeling. Environmental Modelling \& Software 25, pp. 747-759.

Pradhan, B., Lee, S., and Buchroithner, M. F., 2009, Use of geospatial data for the development of fuzzy algebraic operators to landslide hazard mapping: a case study in Malaysia. Applied Geomatics, v. 1, pp. 3-15.

Regmi, N. R., Giardino, J. R., and Vitek, J. D., 2010, Modeling Landslides Using the Weight of Evidence Approach: Western Colorado, USA, Geomorphology, v. 115, pp. 172-187.

Remondo, J., González, A., Ramón, J., Cendrero, A., Fabbri, A, and Chung, C-J. F., 2003, Validation of landslide susceptibility maps: examples and applications from a case study in Northern Spain. Natural Hazards, v. 30, pp. 437-449.

Saha, A. K., Gupta, R. P., Sarkar, I., Arora, M. K., and Csaplovics, E., 2005, An approach for GIS-based statistical landslide susceptibility zonation - with a case study in the Himalayas, Landslides, v. 2, pp. 61-69.

Sharma, M., and Kumar, R., 2008, GIS-based landslide hazard zonation: a case study from the Parwanoo area, Lesser and Outer Himalaya, H.P., India. Bull. Eng. Geol. Environ., v. 67, pp. 129-137.

Sidle, R. C., 1991, A conceptual model of changes in root cohesion in response to vegetation management. Jour. Environ. Quality, v. 20(1), pp. 43-52.

Soeters, R. and van Westen, C. J., 1996, Slope Instability Recognition, Analysis and Zonation, In: Turner, A. K., Schuster, R. L. (Eds.) Landslides, investigation and mitigation, Transportation Research Board, National Research Council, Special Report 247, pp. 129-177

Stöcklin, J. and Bhattarai, K. D., 1977, Geology of Kathmandu Area and Central Mahabharat Range, Nepal Himalaya, Kathmandu. HMG/UNDP Mineral Exploration Project, Technical Report, 
New York, 64 p.

Süzen, M. L., and Doyuran, V., 2004, A comparison of the GIS based landslide susceptibility assessment methods: multivariate versus bivariate. Environ. Geol., v. 45, pp. 665-679.

Ulak, P. D., and Nakayama, K., 1999, Lithostratigraphy and the evolution of the the fluvial style of the Siwalik Group in the Hetauda-Bakiya Khola area, Central Nepal. Bull. Dept. Geol., Tribhuvan Univ., v. 5, pp. 6-14.

UNDP Nepal, 2010, District map of Dhanusa, Nepal available in http://www.un.org.np/maps/district-maps.

van Westen, C. J., 2000, The modelling of landslide hazards using GIS, Survey in Geophysics, v. 21, pp. 241-255.

van Westen, C. J., and Terlien, T. J., 1996, An approach towards deterministic landslide hazard analysis in GIS. A case study from Manizales (Colombia). Earth. Surf. Proc. Landforms, v. 21, pp. 853-868.

van Westen, C. J., Rengers, N., and Soeters, R., 2003, Use of geomorphological information in indirect landslide susceptibility assessment. Natural Hazards, v. 30, pp. 399-419.

van Westen, C. J., 1994, GIS in landslide hazard zonation: a review with example from the Colombian Andes. In: Price, M. F., Heywood, D. I. (Eds.), Taylor and Francis, London.

Varnes, D. J., 1984, Landslide Hazard Zonation: a review of principles and practice, Commission on landslides of the IAEG, UNESCO, Natural Hazards, v. 3, pp. 61.

von Ruette, J., Papritz, A., Lehmann, Rickli, P. C., and Or, D., 2011, Spatial statistical modeling of shallow landslides-Validating predictions for different landslide inventories and rainfall events, Geomorphology, v. 1331-2), pp. 11-22, doi: 10.1016/j. geomorph.2011.06.010.
Wieczorek, G. F., Gori, P. L., Jager, S., Kappel, W. M., and Negussey, D., 1996, Assessment and management of landslide hazards near Tully Valley Landslide, Syracuse, New York. Proc. 7th Int. Symposium on Landslides, Trondheim. Balkema, Rotterdam, pp. 411-416.

Wu, W. and Siddle, R. C., 1995, A distributed slope stability model for steep forested basins. Water Resour Res, v. 31, pp. 2097-2110.

Yalcin, A., 2008, GIS-based landslide susceptibility mapping using analytical hierarchy process and bivariate statistics in Ardesen (Turkey): Comparisons of results and confirmations. Catena, v. 72, pp. 1-12.

Yao, X., Tham, L. G., and Dai, F. C., 2008, Landslide susceptibility mapping based on Support Vector Machine: A case study on natural slopes of Hong Kong, China, Geomorphology, v. 101(4), pp. 572-582.

Yesilnacar, E., and Topal, T., 2005, Landslide susceptibility mapping: A comparison of logistic regression and neural networks methods in a medium scale study, Hendek region (Turkey). Eng. Geol., v. 79(3-4), pp. 251-266.

Yin, K. L., and Yan, T. Z., 1988, Statistical prediction model for slope instability of metamorphosed rocks. In: Proceedings of 5th Int. Symp. on Landslides, v. 2, pp 1269-1272.

Zêzere, J. L., Rodrigues, M. L., Reis, E., Garcia, R., Oliveira, S., Vieira, G., and Ferreira, A. B., 2004, Spatial and temporal data management for the probabilitic landslide hazard assessment considering landslide typology, In: Lacerda, W. A., Ehrlich, M., Fontura, S. A. B., Sayão, A. S. F (Eds.), Landslides: Evaluation and Stabilization, v. 1, pp. 117-123

Zhu L., and Huang J. 2006, GIS-based logistic regression method for landslide susceptibility mapping in regional scale. Jour. Zhejiang Univ., Science A, v. 7(12), pp. 2007-2017. 